Portland State University

PDXScholar

\title{
A Study of Behavior Changes Among Children Who Have Left the Children's Psychiatric Day Treatment Center
}

Julia A. Jones

Portland State University

Larry G. Pederson

Portland State University

Follow this and additional works at: https://pdxscholar.library.pdx.edu/open_access_etds

Part of the Social Work Commons

Let us know how access to this document benefits you.

\section{Recommended Citation}

Jones, Julia A. and Pederson, Larry G., "A Study of Behavior Changes Among Children Who Have Left the Children's Psychiatric Day Treatment Center" (1977). Dissertations and Theses. Paper 1921.

https://doi.org/10.15760/etd.1921

This Thesis is brought to you for free and open access. It has been accepted for inclusion in Dissertations and Theses by an authorized administrator of PDXScholar. Please contact us if we can make this document more accessible: pdxscholar@pdx.edu. 
A STUDY OF BEHAVIOR CHANGES AMONG CHILDREN WHO HAVE LEFT THE CHILDREN'S PSYCHIATRIC DAY TREATMENT CENTER

by

Julia A. Jones

Larry.G. Pederson

A practicum submitted in partial fulfillment of the requirements for the degree of

MASTER OF SOCIAL WORK

Portland State University

1977 
TO THE OFFICE OF GRADUATE STUDIES AND RESEARCH:

The practicum advisor approves the research report, A Study of Behavior Changes Among Children Who Have Left The Children's Psychiatric Day Treatment Center, by Julia Jones and Larry Pederson, presented June 10, 1977.

APPROVED :

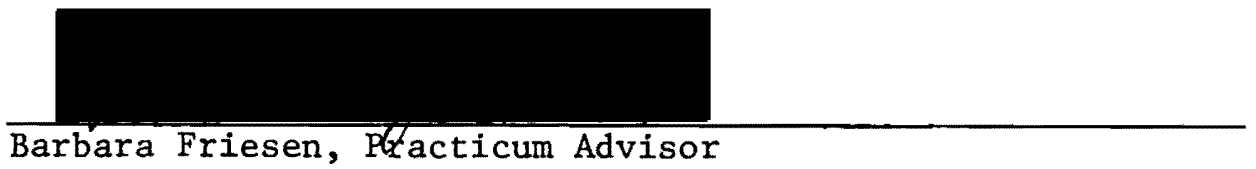




\section{ACKNOWLEDGEMENTS}

The authors wish to express their appreciation to the entire clerical and treatment staff at the Children's Psychiatric Day Treatment Center without whose help and cooperation this study would not have been possible. Particular consideration is extended to Dr. Anita Lohman for whose time, patience, and support we are grateful.

Thanks also to Ms. Barbara Friesen and Dr. Frank Miles. The advice of each has been indispensable to the completion of this study. 


\section{LIST OF TABLES}

TABLE

PAGE

I Distribution of Population According to Age and Sex. . . . 18

II Diagnosis at Intake and Termination. . . . . . . . . 19

III Parent Involvement During Day Treatment and Positive

Behavior Change Between Entry and Termination . . . 43

IV Parent Involvement During Day Treatment and Behavior

Change Between Termination and Follow-up. . . . . 45

V Diagnostic Category at Entry and Behavior Change Between

Entry and Follow-up . . . . . . . . . . 48

VI Behavior Change Between Termination and Follow-up and

Number of Months Since Termination. . . . . . . 49 
TABLE OF CONTENTS

PAGE

ACKNOWLEDGEMENTS. . . . . . . . . . . . . . . . . . . . iii

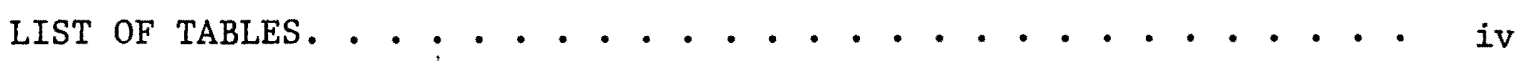

CHAPTER

I INTRODUCTION. . . . . . . . . . . . . . . . 1

II REVIEW OF THE LITERATURE. • . . . . . . . . . . . . 3

The Rationale for Day Treatment . . . . . . . 3

The Variables of Parent Involvement and

Family Disruption . . . . . . . . . . . 5

Some Other Related Studies. . . . . . . . . . 6

III THE SCOPE OF THE STUDY. . . . . . . . . . . . . . 12

The Purpose . . . . . . . . . . . . 12

The Setting . . . . . . . . . . . . 15

IV METHODOLOGY . . . . . . . . . . . . . . . . 17

The Population. . . . . . . . . . . . 17

The Design. . : . . . . . . . . . . 20

Operationalization of Major Variables . . . . . . 21

Description of the Primary Instrument . . . . . . 24

Part I - Parent Interview Schedule . . . . 25

Part II - Family Stress Schedule . . . . . 25

Part III - The Adapted Walker. . . . . . . 26

Reliability of Part III. . . . . . . . 31

Procedures. . . . . . . . . . . . . . 31 
Data Collection. . . . . . . . . . 34

Test Time One................ 34

Test Time Two ........... 34

Test Time Three........... 35

Behavior Changes in the Treatment Population . . . 37

Behavior Changes During Treatment .... . 37

Stability of Behavior Changes After

Treatment ........... 39

Behavior Changes Between Entry and

Follow-up . . . . . . . . . . 40

Behavior Change and Parent Involvement . . . . . . 41

Parent Involvement and Behavior Change

During Treatment. . . . . . . . 41

Parent Involvement During Treatment and

Stability of Behavior Change Between

Termination and Follow-up . . . . . . . . 44

Parent Involvement After Treatment and

Behavior Change Between Termination

and Follow-ip .......... 45

Family Disruption and Stability of Behavior

Change After Treatment .......... 47

Additional Findings. . . . . . . . . . 48

Diagnostic Category and Behavior Change ... 48

Behavior Change and Length of Time

Between Termination and Follow-up . . . . . . 49

VI DISCUSSION AND CONCLUSIONS . . . . . . . . . . 51

Discusston of Principal Findings. . . . . . . . 52

Discussion of Additional Findings . . . . . . . 50 
Behavior Change by Diagnostic

Category. . . . . . . . . . . . 60

Behavior Change and Length of Time

Since Termination From Day Treatment. . . . . 63

Sumary. . . . . . . . . . . . . 64

FOOTNOTES. . . . . . . . . . . . . . . . 67

A SELECTED BIBLIOGRAPHY. • • • • • • • • • • • • • • • • • • 71

APPENDIX I: PARENT INVOLVEMENT SCALE. • . . . . . • . • . • . 75

APPENDIX II: PRIMARY INSTRUMENT • . • . . . . . . . . . . . 79

APPENDIX III: CARETAKER INTERVIEW SCHEDULE. • . • . . . • • . 85

APPENDIX IV: CORRESPONDENCE . . . . . . . . . . . . . . . 88

APPENDIX V: CONSENT FORM. . . . . . . . . . . . . . . 95

APPENDIX VI: CHILDREN'S SCORES ON THE ADAPTED WALKER AND THEIR

CHANGE SCORES. . . . . . . . . . . . . . . 96

APPENDIX VII: TEACHER, PARENT, AND INSTITUTIONAL RATINGS ON THE

ADAPTED WALKER FOR TEST TIME THREE. • • • • • • • 98

APPENDIX VIII: PARENT INVOLVEMENT BETWEEN TERMINATION AND FOLLOW-UP

AND BEHAVIOR CHANGE BETWEEN TERMINATION AND

FOLLOW-UP. . . . . . . . . . . . . . . 100

APPENDIX IX: FAMILY STRESS AND BEHAVIOR CHANGE BETWEEN TERMINATION

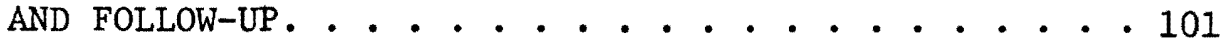


CHAPTER I

\section{INTRODUCTION}

This study began with the authors' interest in the Portland Public Schools' program for Emotionally Handicapped children. Originally, the researchers were interested in assessing behavioral characteristics and changes among children in that program and in relating these variables to the kind and extent of parental involvement. Such a study was particularly timely, it was felt, since some schools were considering eliminating the parent involvement component of the program and there was discussion of phasing out the entire program as it then existed in favor of "mainstreaming." The researchers soon discovered the paucity of research information relating to program effects on children after their termination and realized that program changes might well happen for political and subjective reasons in the absence of research data. Unfortunately, recent changes in Oregon Law relating to confidentiality, in addition to administrative and funding difficulties in the schools forced an upper level decision to curtail outside research in the school system. In September of 1976 the authors were left with an interest and a partially formulated research design but no program within which to apply their design.

At this point the researchers contacted the Childrens' Psychiatric Day Treatment Center in Portland (C.P.D.T.C.) and presented a preliminary plan for research to that agency's Administrative Committee. They received the agency's approval to pursue research relating to children 
who had been in that program and were able to begin the present study in early October.

The present study undertakes to measure behavior changes among the forty-one children who had left the Center during the previous two years and to relate the stability of these changes to subsequent events in the childrens' home lives and to the degree of their parents' involvement in their treatment: 
CHAPTER II

REVIEW OF THE IITERATURE

This literature review focuses on 1 ) the rationale for day treatment, 2) the main variables of parent involvement and family disruption as they relate to treatment outcomes, and 3 ) the design and results of some other studies which have attempted to examine treatment outcome and the factors affecting it.

THE RATIONALE FOR DAY TREATMENT

The goal of most child treatment is the return of children to happy family lives. Children in day treatment are continuously in the process of adjusting to their family systems. This process is one that children in residential care have little exposure to and one which often defeats residential treatment gains. Whittaker outlines three guiding assumptions applicable to child treatment:

1) The basic purpose of residential and day programs for troubled children should be to function as a family support system. rather than to treat the child in isolation from his family and home community.

2) Successful treatment program will be those that actively seek to develop linkages with the other major systems in which the child participates: school, peer group, juvenile justice system, recreation/occupational system.

3) Child treatment programs should focus on growth and development in the child's total life sphere, rather than on the amelioration of psychiatrically defined syndromes or the extinction of certain problematical behaviors. (Whittaker, 1975) ${ }^{1}$ 
Because of high recidivism, high expense, and low public support, Whittaker $(1973)^{2}$ urges a shift from residential treatment as a means of providing therapy to "special children" to residential treatment as a part of growth supporting continuum of child services. 'Such a service continuum would focus on child development instead of child illness and on community support instead of isolation of problem children. The day treatment center would be a central part of such a service continuum.

Mostakas, $(1955)^{3}$ in a national survey done in 1951 , estimated that there were 72 nursery schools for exceptional children at that time in the United States. Included in this number were schools for the physically handicapped as well as the mentally retarded and the emotionally maladjusted. Only 19 states were listed as having such schools. None were listed for Oregon, Washington, Idaho, Montana, or Utah. Enrollment in those schools which did exist averaged twenty children or less for each facility.

Nine years ago it was estimated that there were 12,350 preschool aged children in Oregon needing some form of mental health service. of this number approximately 950 were seen as needing residential. treatment. (Mental Health Division, 1959) ${ }^{4}$ Based on these estimates it is likely that at present there are between 1,000 and 1,500 preschoolers in Oregon needing residential psychiatric care in one form or another. Another study conducted in 1965 revealed a severe shortage of treatment spaces on Oregon for severely disturbed children. It was indicated that aside from a 2.5 fold increase in residential spaces, the following were recommended in order to provide services: 
400 day treatment spaces; 110 therapeutic nursery spaces; 165 therapeutic foster family spaces; 210 special home help spaces; only a handful of any of these (were then) available or in the planning stage. (Taylor, 1965) ${ }^{5}$

Since 1965, several day treatment facilities for Oregon's emotionally disturbed children have been developed. This is consistent with the national movement toward community based treatment for both children and adults. Interestingly this movement has not brought with it a great deal of research activity attempting to examine treatment outcomes and those variables in the community likely to affect them.

\section{THE VARIABLES OF PARENT INVOLVEMENT AND FAMILY STRESS}

of the several factors known to affect the origin and treatment of emotional disturbance in children, many authorities consider the family and its functioning among the most important. (Despert, 1970; ${ }^{6}$ Maclay, $1970 ;^{7}$ Gardner, $\left.1973,{ }^{8}\right)$ Given the family's importance to a child's treatment one can assume that certain family characteristice are conducive to minimizing and destabilizing treatment gains. Family involvement in treatment and family stability will be associated with achievement and maintenance of treatment gains. Family resistance and family disruption will be associated with minimal and unstable treatment gains for the purposes of this study.

There are numerous references in the literature to the far-reaching effects of family disruption. Holmes $(1971)^{9}$ has demonstrated a statistically significant relationship between "life change" thought to produce emotional stress, and the later onset of physical illness. A positive relationship between stress produced by an unstable environment and emotional problems in children has been discussed extensively by Lazarus 
$(1966)^{10}$ and Tanner (1960) ${ }^{11}$ among others. Kiliman (1968) ${ }^{12}$ defined certain family attributes which may be most disruptive for children. These include illness in the family, the absence of a significant member by death, divorce, or other circumstance, and socioeconomic deprivation of either a chronic or crisis nature. Wolff $(1969)^{13}$ also sees these specific factors as stress producing and as resulting in emotional disturbance for many children.

In discussing parent involvement Wolff further notes that "when the main causes of a child's psychiatric disturbance are his parents' attitudes and behaviors, no amount of treatment directed at the child alone will succeed unless this parent can be helped to change also." 14 Green $(1972)^{15}$ after examining several day treatment facilities in an attempt to determine which program components were deemed most "therapeutic" concluded that the capacity of the program to relate to and involve children's parents was one of the four most important common aspects. Bridgeland $(1971)^{16}$ in a thorough review of educational treatment of maladjusted children in Britain also stresses the importance of extensive contact between family and program if treatment is to be successful. Lansing $(1967)^{17}$ in studying psychotic preschoolers confirms this notion and indicates that it applies to numerous modes of intervention. This likely relates to Whittaker's thesis that the most successful treatment programs are those which integrates most completely into community support systems.

SOME OTHER RELATED STUDIES

The few day treatment follow-up studies reported in the literature to date do not clearly confirm the benefits of parent involvement or the 
destructiveness of family stress. Those studies which, have been done indicate the difficulty of objectively assessing behavior changes. These changes of course must be assessed with some accuracy before their probable causes can be realistically explored.

Truitt (1928) ${ }^{18}$ made an early attempt to 1 ist the problem behaviors of children in treatment. Behaviors described ranged from thumbsucking to "wanderlust" and included a total of forty items. Unfortunately many of the behaviors were unclearly defined and the author mentioned no attempts to measure the relationship between treatment and the continued incidence of the behaviors noted.

Even if behaviors are clearly defined, Blanton (1975) ${ }^{19}$ and Treffert $(1973)^{20}$ note the importance of attending to diagnostic categories when trying to evaluate behavior changes in groups of children. Blanton notes that many methods of classifying performance abnormalities do not distinguish between the emotionally disturbed and the mentally retarded, two groups which have markedly different prognoses. Treffert, after studying 57 disturbed children in a hospital setting, found that children with early infantile autism tended to remain chronically disturbed compared to children with later onset. Similarly. Kohn $(1970)^{21}$ after studying 407 children in public day care found that disturbed children classified as aggressive were less able to use teacher support to change their behavior than were disturbed children classified as passive. There is some evidence then, that the kind of screening a program does at intake will have some effect on the degree and kind of behavior change to be expected at follow-up. Not all studies of treatment outcome take this into account. Baumann $(1975)^{22}$ reports on a study of 67 severely disturbed children who spent an average of two years in day treatment. Seventy-nine 
percent were surviving in public schools at the time of follow-up. The goal of the study was to describe the children's initial status, their progress, and their status at the time of follow-up. Data about progress while in the program was taken exclusively from case records and included reviews of treatment summaries, intake studies, and psychological, psychiatric, medical, and classroom reports. Follow-up data was based on follow-up reports and a home visit questionnaire dealing with the child's current behavior, family interactions, and family attitudes. While describing the important variables of family behavior and psychiatric diagnosis, the study is unclear about what kinds of treatment outcome these variables relate to. The instrument designed to assess children's behavior at follow-up was not used at time of entry and termination; therefore the assessment of behavior change is based on two types of data gathered over time making the results less objective. As with most studies of this type of population no control group was used. Hyman $(1973)^{23}$ reports one of the few studies of a day treatment population using a form of control group. Sixteen program children were matched for symptom commonality, age, sex, intelligence, and socioeconomic status with a comparison group of eleven non-program children. The goal of the study was to determine if program intervention produced significant differences in school adjustment. Behavior change at follow-up was measured by a 37 item behavior checklist. The validity of this instrument was established by the consensus of the professionals involved in the research. Apparently no other means of validating the instrument was used nor was mention made of the instrument's reliability in the study abstract. Individual checklist items were, however, related to reasons for referral of children to the program. Hyman found that the 
program children improved significantly on 6 of the 37 behaviors 1isted. Unfortunately, no attempt to relate behavior change-or lack of it-to family variables was mentioned. Also, no comparison was made between diagnostic categories of children and specific behavioral improvements. As noted previously, treatment outcome can depend on the kinds of children being treated.

Furman (1969) ${ }^{24}$ describes one of the most detailed follow-up studies on children in day treatment yet available. Sixty-two children were rated with Anna Freud's Developmental Profile (1963) at the time of their preschool age entry into the program, at the time of their graduation from the program, and finally at the outset of puberty. Information from the first two samplings came from clinical records. Puberty age information came from direct interviews. Results, although lacking the objectivity of direct behavioral measurement, tended to confirm the hypothesis that preschool aged children in day treatment fare significantly better if their parents become an integral part of. the treatment-change atmosphere. This was especially true when emotional disturbances were of greater severity than transitory developmental conflicts. These findings are consistent with the assumption of Green, Brigland, and Lansing, noted previously, regarding the Importance of parent involvement.

Like Hyman, Furman used a single instrument to measure behavior at entry, termination, and follow-up; a method assumed to yield more reliable results than the narrative style of the Baumann study. Also, Furman notes that the Developmental Profile should help to control for behavior changes due to maturation and not to treatment. Distinguishing between program effects and maturation effects was a problem reported by 
Duke $(1973)^{25}$ when she attempted to assess treatment outcome for 12 previously institutionalized children 10 years after treatment. One might question, however, the results of any study attempting to measure treatment effects several years after the treatment has happened if no control group is used. Maturation becomes an increasingly important confounding variable and the instrument used to measure the behavior of a given child must be sufficiently abstract to account for changes in behavior patterns with age while measuring the assumed effects of treatment. For studies not using a control an alternative would be to simply employ a shorter time period between treatment and initial followup as Duke has suggested.

Johnston and Shilling (1975) $)^{26}$ also raised the question of instrument validity when they attempted to assess behavior changes among children in three classrooms for the emotionally handicapped. After using the Hewett Behavioral Checklist to measure behavior change and finding no significant changes among program children, they surmized that the instrument used perhaps did not measure the kinds of specific behaviors that such programs attempted to change. The Walker Problem Behavior Checklist $(1970)^{27}$ was suggested as more appropriate for use in programs for emotionally disturbed children.

In summary, the literature documents a movement toward meeting, the need for treatment programs for seriously disturbed children in Oregon and elsewhere. Many planners feel that these programs are most successful if they are community oriented and recognize the importance of children's families to treatment outcome. Other professionals in the field have isolated specific family related variables thought to effect treatment outcome. Generally speaking, these include family disruption and 
family involvement in the treatment process.

As is often the case, the amount of theoretical information available exceeds the amount of research that has been done. There is a dearth of research in the field about the outcome of day treatment. The research that has been done has typically been plagued by poor or inconsistent instrumentation, or failure to take into account the main variables thought to influence the outcome of day treatment. 
CHAPTER III

THE SCOPE OF THE STUDY

PURPOSE

The present study is based on three assumptions. (1) Certain observable behaviors are characteristic of children who fail to survive at home or at school. Failure to survive in this case means having adjustment problems necessitating alternative placement. (2) Decreases in the incidence of these behaviors correspond positively to children's survival at home and at school. (3) Certain environmental factors can be isolated that relate to increases or decreases in these behaviors and to the stability of behavior change.

The purposes of this study are as follows:

(1) To measure the incidence of "problem behaviors" among children during and subsequent to their involvement in a day treatment program.

(2) To measure the stability of changes in the number and frequency of "problem behaviors" among these, children after they have left a day treatment program.

(3) To relate behavior change and the stability of behavior change to the environmental variables of parent involvement and family stress. To accomplish these purposes, the following guiding hypotheses were formulated: 
Hypothesis 1: "Problem Behaviors" will decrease between entrance into and termination from the Day Treatment Center.

Hypothesis 2:. Decreases in "problem behaviors" between entrarice into and termination from the Day Treatment Center will be maintained subsequent to termination.

Hypothesis 3: Children whose parents demonstrate "high" involvement during day treatment will show higher "positive behavior change" during treatment than will children whose parents demonstrate "low" involvement in the Day Treatment Program.

Hypothesis 4: Children whose parents demonstrate "high" involvement during day treatment will show greater "positive behavior change" or less "negative behavior change" after day treatment than will children whose parents demonstrate "low" involvement in the Day Treatment Program.

Hypothesis 5: Children whose parents demonstrate "high" involvement in their children's school or treatment program after termination from day treatment will show greater "positive behavior change" or less "negative behavior change" after day treatment than will children whose parents demonstate "low" involvement after treatment.

Hypothesis 6: Children who experience less "family stess" after day treatment will demonstrate greater "positive behavior change" or less "negative behavior change" after day treatment than will children who experience more "family stress."

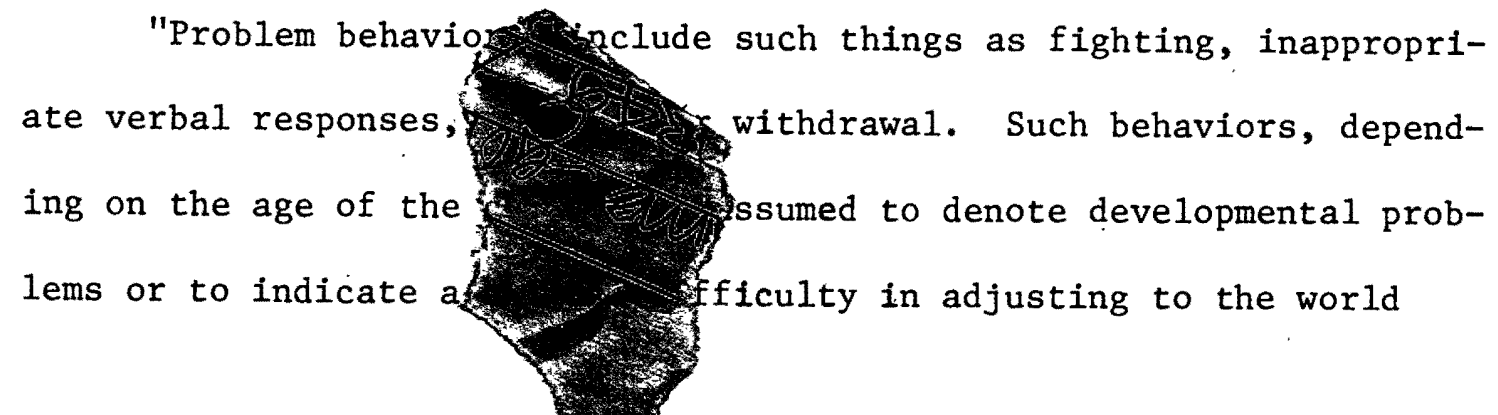


around him. The means of arriving at the representative list of behavior items used in this study will be discussed later.

"Negative behavior change" and "positive behavior change". denote changes in the incidence of "problem behaviors" during the time periods defined for the purposes of this study.

"Parent involvement" indicates the means and extent of parents' relatedness to their child's treatment. Parents might receive therapy themselves or they may have conferences with staff or classroom visits with varying degrees of frequency. These types of contact with the child's program may or may not continue after the child is terminated from day treatment.

"Disruptive family changes" include such things as moves, serious illnesses, and significant people entering or leaving the household. The means of measuring these family changes as well as parent involvement will be discussed more completely in the methodology section.

It may be important to note that this study does not attempt to evaluate the overall effectiveness of the Day Treatment Program. It merely tries to describe specific behavior changes among children who have gone through the program. Similarly, it would be presumptuous to assume that an increase or decrease in "problem behaviors" among the children studied indicates success or failure in their lives in general. It is simply assumed that decreases in these behaviors enhance a child's chances of surviving at home and at school.

Finally, it must be made clear that this study will not at tempt to establish a causal relationship between parent involvement, family disruption, treatment program, and changes in "problem behaviors". The results herein are only suggestive and should be followed up by more 
controlled and definftive studies.

THE SETTING

As noted in a recent Program Review $(1976)^{28}$ the Children's Psychiatric Day Treatment Center was developed by the University of Oregon Medical School as a facility for teaching child behavior and child psychiatry. Since beginning 1970 , the Center has attempted to fill this function in addition to providing a needed community service and acting as a model for other child treatment facilities. The agency's philosophy is based on a developmental conceptualization of child behavior inasmuch as treatment goals and objectives derive from a child's perceived locus on a developmental continuum.

Between 1971 and 1976 the Center had provided services to more than 80 children. The average 1975-1976 population of 17 children did not include an average of 13 children receiving intensive follow-up services for that year. Children are enrolled in the program on a yearround basis and usually participate in the milieu component 9:00 A.M. to 2:00 P.M., 5 days per week. Length of stay ranges from nearly 30 months on the average for psychotic children to just over 14 months for non-psychotic, non-organically affected children.

Treatment personnel include psychiatrists, psychologists, child care workers, teacher/therapists, and social workers. Treatment modes include milieu therapy, play therapy, psychotherapy, family therapy, group therapy, child management instruction, and parent education in addition to community consultation and coordination services. Treatment inputs are coordinated by and administered through teams of the professionals noted. 
Since the Center is committed to a community oriented approach to child treatment, parent involvement in the program is required. Treatment planning involves the active participation of parents as staff and parents work together to help the child achieve treatment goals at home and at school. As noted this orientation is pursued further through the use of a multidisciplinary approach in the community and in the past has been strengthened by the efforts of a follow-up team which attempted to successfully reintegrate the child into his or her public school. 
CHAPTER IV

METHODOLOGY

This chapter deals primarily with the development and use of the instruments which were designed to collect significant information on the population in this study. The procedures used in the collection of data, a description of the population and other important aspects in the development of the research design will also be covered in this section.

\section{THE POPULATION}

The sample studied includes thirty-three of the forty-one chilren who have left the Day Treatment Center between 1974 and 1976. Information was not available on eight children due to circumstances which are discussed later in the chapter. This two-year period was chosen for several reasons. First, during this time, CPDTC has been accredited by the Joint Commission on the Accreditation of Hospitals (JCAH). This accreditation required among other things, that each rocord contain consistent information and documentation. For the purposes of this study, this documentation provided the basis for the assessment of behavior at the time of entrance and time of termination from the program. Secondly, prior to this time, there had been a readjustment in program management and organization. The period since this reorganization has provided the researchers with a stable and consistent program in which the present study took place. Furthermore, it was noted that there would be greater accessibility to the children's parents, 
legal guardians, or caretakers and teachers in the two-year period as opposed to a longer time span.

of the original 41 children, 10 were female and 31 were male. The average age of children upon admission into the program was 6.01 years with a range from 3 years and 1 month to 9 years and 1 month. (See Table I) The average length of stay was $21 \frac{1}{2}$ months with a range of stay of 4 to 47 months.

TABLE I

DISTRIBUTION OF POPULATION ACCORDING TO AGE AND SEX

Sex Number of Children

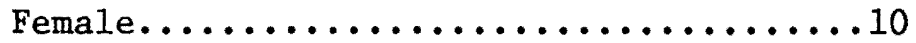

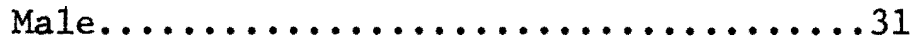

Age Upon Admission Number of Children

3 yr. 1 mo. -4 yr. ............ 4

4 yr. 1 mo. -5 yr. .................. 9

5 yr. 1 mo. -6 yr. .............. 7 .

6 yr. 1 mo. -7 yr. $\ldots \ldots \ldots \ldots \ldots \ldots \ldots \ldots 7$

7 yr. 1 mo. -8 yr. ............... 3

8 yr. 1 mo. -9 yr. .............. 10

9 yr. 1 mo. -10 yr. ............... 1

The majority of the children were diagnosed as having situational reactions both before and after treatment. (See Table II) It is interesting to note that at termination approximately $17 \%$ of the children were judged to have no mental disorder. 
TABLE II

DIAGNOSIS AT INTAKE AND TERMINATION

Number of Children

Diagnosis Initial Diagnosis Final Diagnosis

$\begin{array}{lrr}\text { Behavior Disorder } & 14 & 9 \\ \text { Depressive Neurosis } & 1 & 0 \\ \text { Mental Retardation } & 2 & 2 \\ \text { Organic Brain Syndrome } & 3 & 3 \\ \text { Situational Disturbance } & 13 & 14 \\ \text { Schizophrenic } & 7 & 6 \\ \text { No Mental Disorder } & 0 & 6 \\ \text { None } & 1 & 1\end{array}$

During treatment, 11 children were living with foster parents, 25 children lived with their natural parents, 4 children lived with their grandparents, and 1 child lived in a residential treatment center. Presently, 23 live with their natural parents, 5 children live with foster parents, 2 live with other relatives and 6 children live in residential treatment centers. Current information on the living situations of 5 children was not available to the researchers.

As noted earlier, complete information regarding all forty-one children was not available due to a number of circumstances. Five children and their parents/legal guardians could not be located. In 3 cases, the parents refused to be interviewed. One family refused to be interviewed because of a recent family crisis, whereas in the other cases, the parents refused because of their dissatisfaction with the program and staff and furthermore felt that their child did not benefit from the Day Treatment Program. Therefore, the researchers were unable to obtain data on 8 children.

In addition, one family refused to give permission to contact the child's teacher since the child had been suspended from school. However, 
the researchers obtained family information about this child.

The children were not directly involved in the study (i.e. children were not interviewed). Parents, legal guardians, caretakers, and/or school teachers were the key persons the researchers contacted for information.

\section{THE DESIGN}

The present study is designed to gather information about children at three different points in time: Test Time One (Time 1) when the child entered the Day Treatment Program, Test Time Two (Time 2) when the child left the program, and Test Time Three (Time 3) when the researchers obtained information about the child's current behavior at home and within the school or within residential treatment centers.

The study is based on six hypotheses:

1. "Problem Behaviors" will decrease between entrance into and termination from the Day Treatment Center.

2. Decreases in "problem behaviors" between entrance into and termination from the Day Treatment Center will be maintained subsequent to termination.

3. Children whose parents demonstrated "high" involvement during day treatment will show higher "positive behavior change" during treatment than will children whose parents demonstrated "low" involvement in the Day Treatment Program.

4. Children whose parents demonstrate "high" involvement during day treatment will show greater "positive behavior change" or less "negative behavior change" after day treatment than will children whose parents demonstrate "low" involvement in the Day Treatment Program. 
5. Children whose parents demonstrate "high" involvement in their children's school or treatment program after termination from day treatment will show greater "positive behavior change" or less "negative behavior change" after day treatment than will children whose parents demonstrate "low" involvement after treatment.

6. Children who experience less "family stress" after day treatment will demonstrate greater "positive behavior change" or less "negative behavior change" after day treatment than will children who experience more "family stress."

\section{OPERATIONALIZATION OF MAJOR VARIABLES}

Problem behaviors are assumed to block the child's growth and development and to denote emotional disturbance in the child. These behaviors include such things as fighting, inappropriate verbal responses, enuresis, and withdrawal. The frequency of problem behaviors was measured using Part III of the primary instrument. A complete description of the primary instrument follows this discussion. The child received a score based on the addition of the frequency ratings on 34 behavioral items at three points in time. These three scores were compared for differences between the time periods and this change score indicated if a decrease or increase in problem behaviors had occurred. The respective change scores were computed by subtracting the problem behavior scores at Time 1 from Time 2 and subtracting the problem behavior score at Time 2 from Time 3.

"Positive behavior change" indicates a positive change score between time periods whereas a "negative behavior change" denotes a negative change score between time periods. 
The researchers further predicted that parental involvement in a child's treatment process would increase the likelihood of a positive change in "problem behaviors." As defined earlier, parental involvement indicates the means and extent of parents' relatedness to their child's treatment and includes such things as telephone contacts, classroom visits, conferences, and therapy with the individual parents.

Parental involvement was measured at two different periods: involvement during treatment at CPDTC and current involvement in the child's treatment if such help was occurring. The first period was measured by the use of the Parental Involvement Scale (See Appendix I). Present CPDTC staff members who worked with these children and three persons once employed with CPDTC were asked to judge the involvement of the parents (either high, or low involvement or not applicable) using the following instructions for completing the Parent Involvement Scale:

1. Consider the different ways the parents relate to the program (phone calls, management meetings, individual sessions, classroom visits, etc.).

2. Consider how often parents used these means of being involved with the program (missed appointments, unavailability, unwilling to participate in certain modes of treatment).

3. Consider parents' ability of willingness to make use of the different types of involvement (whether they were active or passive during contacts, whether contacts seemed productive or non-productive).

4. Since children are in the program for a number of months and in some cases, years; try to arrive at an average of the above considerations for the entire length of a child's stay. 
5. If children have been placed outside their homes for a significant period during their stay, consider the involvement of the surrogate parents.

These questionnaires were computed by the researchers and the parents were placed into one of two categories: high involvement or low involvement. In two cases, the parents were rated equally as high involvers and low involvers. The researchers randomly placed one in the high involvement category and one in the low involvement category.

A different method was used to determine current parental involvement. When a child was presently in treatment, the frequency of parental involvement per month was used to measure high, medium, or low involvement. The involvement index ranged from 0 (indicating no treatment contacts) to 22.75 (indicating 22.75 parent contacts per month) with a median of 3 .

Family stress or disruptive family changes were determined by the number of important family changes occurring since the child left CPDTC. Such changes included; changes in location, change in the family's income, illness or death in the family, and loss or addition of a significant. other in the household.

An index indicating family stress was derived by totaling the number of such changes and dividing this number by the number of months the child had been out of the Day Treatment Program. This index was multiplied by 100 and the stress-factor for each child was obtained. The stress-factor ranged from 0 (indicating no family changes) to 100 (indicating 1 family change per month since the child left the program) with a median of 16.7 . 
The primary instrument (See Appendix II) was designed to gather data on these major variables at three different points in time. The additional Parent Involvement Scale was employed to measure parent involvement during the child's treatment at CPDTC. A detailed description of the primary instrument follows.

\section{DESCRIPTION OF THE PRIMARY INSTRUMENT}

The primary instrument (See Appendix II) is divided into three sections. Parts $I$ and II consist of open-ended questions while Part II contains 34 behavioral descriptions with a seven point rating scale. The instrument was initially designed so that it could be mailed if individual interviews with parents, guardians, caretakers or teachers could not be obtained. However, where possible, it was the researchers' intent to use the instrument as an interview schedule rather than a mailed questionnaire.

Pre-testing of the instrument occurred with two individuals not associated with the Day Treatment Center or the social work/mental health fields. Their responses were used to clarify several questions on Part II of the interview schedule resulting in further revision of the primary instrument. Furthermore, a final draft of the entire instrument was presented to the CPDTC Administrative Committee for critical analysis.

The two researchers engaged in a role-playing exercise, one playing the part of the interviewee (a mother) and the other acting as the researcher. This occurred in order to insure a reliable uniformity and consistency in the interviewing approach and to obtain an approximation of the time it took to conduct an interview (about 45 minutes). 
These steps were taken in order to improve the instrument and to provide a consistent interviewing system.

Part I - Parent Interview Schedule

Part I consists of three statements, with two or four additional open-ended questions to be answered if the statement is descriptive of the present situation. It is designed to be used with an interviewer and parent or legal guardian. An alternative Part I section was designed for those children in residential programs covering the same areas. (See Appendix III).

This section solicits information about the types of treatment children and family members may presently be receiving for emotional or behavioral problems. "Treatment" includes professional help, special school classrooms, etc.

The researchers recognize that many of these children may still have problems requiring treatment. Referring to the previously stated hypothesis, it is the researchers' prediction, that children with parents who are highly involved in their treatment will show comparative improvement on Part III.

Part II - Family Stress Schedule

Part II contains five statements which describe possible family changes that have occurred since the child has left the Day Treatment Center. As in Part I, two to four open-ended questions follow each statement and are to be answered if the statement describes the present situation. Again, it is designed to be used with an interviewer and the child's parent or guardian. 
These five statements represent variables which the researchers considered as possible contributing factors to the child's present behavior adjustment. These variables include:

1. Family geographic mobility or relocation.

2. Change in the family income.

3. Serious illness or death within the family.

4. Change in the number of people in the household.

5. Other changes.

As in Part I, an alternative section was designed for children in residential treatment programs (See Appendix III). Since the environments of residential centers are by nature, vastly different from the family home, the reseachers concentrated on the mobility of the child within the residential program and the addition or loss of significant others. These variables correspond to numbers 1,3 , and 4 of the Family Stress Schedule, Part II.

Part III - The Adapted Walker

Part III includes 34 behavioral descriptions adapted from the Walker Problem Behavior Identification Checklist and a 7 point rating scale numbered from 1 to 7 with a definition describing each point on the scale as follows:

1. Constantly - Behavior is seen constantly throughout the day.

2. Very Frequently - Behavior is seen at least once a day.

3. Frequently - Behavior is seen at least once a week.

4. Sometimes - Behavior is seen more often than once a month, but less than once a week.

5. Occasionally - Behavior is seen at least once a month. 
6. Seldom - Behavior is seen less than once a month.

7. Never - Behavior does not occur.

This section of the primary instrument was designed to be presented to both parents, legal guardians and teachers or to caretakers in residential programs. Furthermore, the present researchers used this section to rate the child's behavior during the six-week assessment period prior to the development of the formal treatment plan at CPDTC and upon termination from the Day Treatment Center.

Inter-rater reliability was determined between the two researchers for Part III of the instrument in the following manner: two current records were selected since they were not part of the population to be studied. In each record, the Growth Continuum and Integrative Review sections pertaining to the first six-week assessment period were used as bases for rating the child's behavior on the Adapted Walker Scale, at the time of entry into the program. To evaluate the degree of agreement between the two raters on the two children, the results were compared using the following formula:

$$
\frac{\left(R_{1}-R_{2}\right)}{N}
$$

Record I yielded $86 \%$ inter-rater reliability, while Record II yielded $82.5 \%$ reliability. For the purpose of this study, the two researchers were considered to be fairly consistent in their applications of the Adapted Walker to the specific cases noted.

The researchers discussed and clarified their positions on particular items when a great disagreement occurred between behavioral statements, that is, where the difference between the ratings was equal to 

or greater than four points. Decisions were made as to the actual meaning of certain behavioral statements thereby increasing reliability. The need to review the rating scale for an accurate measurement was also recognized.

Hill M. Walker developed the Walker Problem Behavior Identification Checklist (WPBIC) as a means for teachers to identify children with behavioral problems that interferred with or competed with the child's academic performance. The fifty behavioral items on the WPBIC are the result of a pool of 300 descriptive observations of students' overt behaviors (interfering with the child's academic performance) obtained from a random sample of thirty teachers. These fifty items represent the most frequently mentioned behaviors from the sample. Furthermore, the fifty items are categorized into five classes: acting out, withdrawal, distractability, disturbed peer relations and immaturity. (Walker, $1970)^{28}$

Walker also assigned "weights" for each of the fifty items. He selected a panel of five behavioral scientists who rated the individual items on the basis of a 20 point scale, ranging from "of no importance" to "of great importance." The judges' item ratings were pooled and averaged so that each item was assigned a score weight ranging from 1 (less important) to 4 (important). (Walker, 1970) 29

In the development of Part III, the researchers rejected several of Walker's behavioral descriptions and added two new descriptions. The development of this "Adapted Walker" was based on several factors. First "key staff" (those staff members on the Administrative Committee) gave the researchers input on those behavioral items they felt were important. These were behaviors that staff most frequently worked on with children 
in treatment. Furthermore, they pointed out that some behavior items required verbal ability which some of the sample population did not have due to age, organic disabilities and so on. These statements were rearranged in such a manner as to include nonverbal implications or were completely eliminated. It was also noted that some of the items were "normal" behaviors in particular developmental stages. These items were either eliminated or cited as being "abnormal" only if observed in the extreme (i.e., constantly or never).

Secondly, the researchers used Walker's weighting system (Walker, $1970)^{30}$ deleting items with a weight of 1 ("less important") while retaining those items that Walker gave a weight of 4 ("of importance"). This in combination with the staff's comments, was the primary method of selecting items for Part III of the primary instrument.

Walker's employment of the five behavioral scientists in the construction of the WPBIC and his validity measures, plus the researchers selection process of behavioral items and use of the Administrative Committees' recommendations lend support to the Adapted Walkers' validity. From the foregoing, it can be estimated that the Adapted Walker is valid.

In addition, Walker's behavioral items are predominantly negative. He has noted that in a normal population, a positively skewed distribution would be expected. However, it is with interest that Walker recognizes that in a..."residential treatment facility for severely disturbed children, the checklist application could conceivably result in a negatively skewed distribution"... indicating the possession of a large number of deviant behaviors. (Walker, 1970) 31 
Therefore, the researchers changed seven times to positive statements and added two in order to concentrate the study on both strengths and weaknesses of these children. Furthermore, it is conceivable that with a particular child, many of these negative behaviors are characteristic of him or her. This could affect the parent, guardian, caretaker or teachers' ratings in such a manner that she or he might become tracked into marking $1^{\prime} s, 2^{\prime} s$, and/or $3^{\prime} s$ (behavior occurs constantly, very frequently, frequently) on most of the behavioral items.

Another distinct difference between Part III and the WPBIC is the rating scale. The WPBIC does not employ such a scale. On Walker's instrument, if the behavior time is observed in "the child's response patter," the number (indicating the weight of importance) to the right of the statement is circled by the observer. (Walker, 1970) 32

The use of a rating scale provides a number of advantages. As indicated earlier, many of the behavioral descriptions are characteristic of the children in the population. However, the behaviors vary in both intensity and amount. A rating scale measures this variability, whereas,. the WPBIC instructs the observer to circle the number if he or she has observed the behavior within the two month observation period. This completely ignores the frequency of the behavior which, for the purposes of the study, is important in order to measure the degree of change a child has made over a period of time. In other words, the quality of behavior may not change as much as the severity or frequency of the behavior. Therefore, a more sensitive scale was used to detect these more subtle changes. Additionally, the reliability of a scale increases as the number of possible alternative responses increase. (Sellitz, 1959) 33 
Therefore, the 7-point rating scale allows for more reliable and precise information regarding the child's behavior and seemingly provides the interviewee a set of clear and definite directions.

\section{Reliability of Part III}

The reliability of Part III was estimated by the Spearman-Brown prophecy split-half reliability method. Fifteen completed "Adapted Wa1kers" were examined, comparing the even and odd numbered items. These were randomly selected. The following formula was used to measure the reliability of the Adapted Walker:

$$
R=\frac{2 r}{1-r}
$$

The split-half reliability coefficient ( $R$ ) obtained through this procedure was .996 indicating that this section of the primary instrument is highly reliable.

\section{PROCEDURES}

This section briefly deals with the set of procedures used in the collection of data.

Initially, a cover letter was sent to the parents or legal guardians (See Appendix IV) of the treated child, introducing the researchers and giving a short description of the research project. Also enclosed with the letter was a consent form (See Appendix V) in which the parents or guardian agreed to one of the following: 1) researchers may contact the parent, guardian and child's teacher, 2) researchers may contact the parent, guardian and discuss the teacher contact, or 3) researchers may not contact the parent, guardian or teacher. A short 
letter from the director of CPDTC (See Appendix IV) endorsing the study and a stamped envelope addressed to the Center were included with the letter.

These items (consent form and letters) were reviewed by the Portland State University Human Subjects Research Committee. This Committee reviews proposed studies for the purposes of protecting human subjects under the guidelines and regulations of the Department of Hèalth, Education and Welfare.

If the parents or guardians did not respond to this letter, a duplication of the above enclosures was sent together with a second letter (See Appendix IV) which attempted to convey to the parent or guardian that the researchers wanted their opinions, be they positive or negative. If this second letter was not answered, the researchers contacted the parent or guardian by telephone. In cases where the parent or guardian had no phone, a letter was sent (See Appendix IV) setting a time and date when one researcher would visit their home to introduce him or herself, describe the study and request the parents' participation in the project.

Once approval was obtained to interview the parent or guardian, a date and time for the interview was established by telephone. If permission to contact the child's teacher was not granted on the returned consent form (parent checked the second box on the consent form), the researcher discussed the teacher contact with the parent during their interview and in all cases, but one, the researcher was able to obtain the parent's consent.

In contacting the caretakers at the residential treatment centers where 6 children lived, the researchers received permission from the 
child's Children's Services Division worker (See Appendix IV) if the child was a ward of the court. When the child was not a ward of the court and voluntarily placed at the residential treatment. center, the researchers received permission from the parent of the child. In either case, the caretaker was contacted and interview times and dates were agreed upon.

When permission was given to contact the child's teacher, the researchers first contacted the school principal to get his or her permission to mail the Adapted Walker to the teacher. An explanation and description of the study was given to the principal during the telephone conversation with the reassurance that the parents had consented to the researchers contact with the school teacher. Following this contact, the researchers contacted the teacher by telephone and gave him or her a brief explanation about the study and the Adapted Walker that would be mailed if he or she agreed to participate. Following these telephone contacts, a cover letter was sent (See Appendix IV) to the teacher introducing the researchers and giving a short description of the study. Instructions for completing the Adapted Walker were also included in the letter. Other enclosures included the Adapted Walker coded with the child's number in the right hand corner, a copy of the consent form signed by the child's parent or guardian, a slip of paper with the child's name on it reminding the teacher what student was to be considered in completing the Adapted Walker, and a stamped envelope addressed to CPDTC. Additional phone contacts were used to insure the return of completed questionnaries. 
DATA COLLECTION

By means of random selection, the researchers divided the sample population for the collection of data at the three designated times: the time of entrance (Time 1), the time of termination (Time 2), and the time of follow-up (Time 3). One researcher orginally had 21 cases whereas the other had 20. Each child was assigned a code number in order to insure confidentiality.

Test Time One - Time of Entry (Time 1)

The initial six week period when the child entered the program was assessed using the "Adapted Walker." Two sections of the individual's record were used to determine the child's behavior. One section was the Growth Continuum which contains information regarding the child's physical health, intellectual functioning, social behavior, emotional behavior, drive development, self-concept, home environment, motor functioning, parent management skills, and the relationship of the parents with the Day Treatment Center. The Integrative Reviews written within the six week assignment period were also used. These Reviews contained information about the child's behavior.

After thoroughly reading these sections, the researcher completed the Adapted Walker. This activity occurred at the Day Treatment Center and took approximately 30 minutes per record.

Test Time Two - Time of Termination (Time 2)

Termination or Test Time Two was assessed in a similar manner to the time of entrance. Using the child's Termination Summary and Intergrative Reviews pertaining to the last month prior to termination, the 
Adapted Walker was again completed by the researcher. The Termination Summary contains information regarding the child's present behavior, a short report summarizing the child's progress while in the program and the child's final diagnosis.

The Adapted Walker was completed by the researcher, again at CPDTC. This process took approximately 20 minutes per record.

The times of completion of the Adapted Walker for Test Time One and Test Time Two were inconsistent. In some cases, the researchers rated a child at Test Time one and Test Time Two in immediate succession while in other cases, there was a time interval of up to two weeks between the completion of the two ratings. The implications of this inconsistency are discussed in Chapter VI.

Test Time Three - Time of Follow-up (Time 3)

The entire instrument (Parts I, II, and III) was used with parents, guardians and/or caretakers at the third testing point, which assessed the child's most current behavioral pattern. Teachers received Part III by mail as discussed earlier.

The researchers conducted face to face interviews with the parents or caretakers. The interviews varied in terms of where they occurred and with whom they were conducted. In 22 situations, parent interviews occurred in their homes, 2 interviews were conducted at Portland State University and 3 parent interviews occurred at the Day Treatment Center. A11 6 of the caretaker interviews took place in the offices of the caretakers at their respective residential centers.

In 25 situations, the interviews occurred with the child's mother, 1 interview occurred with the child's father, and in 1 case, both parents 
were involved in the interview. When two parents were involved, their consensus in response to a particular question was recorded in the form of a single answer.

In all interviews with the parent or caretaker, the interviewee was given a copy of the primary instrument with the verbal directions that the researcher would read the question or statement aloud and record the interviewee's answer on the researcher's instrument. A copy of the primary instrument was given to the interviewee so that she or he could refer back to it for purposes of clarification. This was of special importance with the Adapted Walker in terms of the rating scale. Many times, it was necessary for the interviewee to refer back to the scale in order to give the most accurate estimation of the frequency of a behavior.

The Adapted Walker was mailed to the child's teacher with instructions given in the cover letter. The scores on the Adapted Walker as filled out by the teacher and parents, were averaged to determine the child's Test Time Three behavioral pattern.

In the pre-planning stages; the researchers had planned a personal interview with the teacher using the Adapted Walker in a manner similar to the interviews with the parents of caretakers. This would have avoided any discrepancies or misinterpretations of the behavioral statements. However, due to the pressures of time, the Adapted Walker was mailed. It was rationalized that teachers probably needed less help in completing the ratings due to their specialized training and familiarity of such procedures. 
CHAPTER V

FINDINGS

The results of this study can be divided into four broad categories and will be discussed accordingly. 1) Behavior changes in the study population occurring during the various phases defined for the purposes of this study; 2) Behavior changes as they related to parent involvement as defined in this study; 3) Behavior changes as they related to family disruption as defined; 4) Additional findings related to treatment outcome but not directly related to the guiding hypotheses mentioned in previous chapters.

\section{BEHAVIOR CHANGES IN THE TREATMENT POPULATION}

The primary study objective was to measure changes in the incidence of a selected number of "problem behaviors" in the treatment population described and then to relate these changes to two major independent variables; parent involvement and family disruption. These changes were examined over two time periods; 1) between entrance into and termination. from the program and 2) between termination from the program and time of follow-up.

Hypothesis 1, Behavior Changes During Treatment

It was hypothesized that "problem behaviors" would decrease between entrance into and termination from the Day Treatment Center for those children studied. The data used were the children's raw scores on the 
Adapted Walker at the time of entrance into the program (Time 1) and the children's scores on the same instrument at the time of their termination from the program (Time 2). (See Appendix VI) As a method for examining the significance of the difference between the means of Time 1 raw scores and Time 2 raw scores, a $\mathrm{T}$ test was performed. It was possible to use this procedure instead of one less reliable since $\mathrm{N}$ exceeded 30 . $\mathrm{T}>1.6$ would indicate a significant difference between Time 1 scores and Time 2 scores at $\mathrm{P}=.05$. (Dornbusch, 1955) 34

The means. for Time 1 and Time 2 raw scores were 141.4 and 175.97 respectively. (See Appendix VI) $\mathrm{T}=7.54$ between the Time 1 scores and the Time 2 scores indicated a significant difference at $\mathrm{P}=.01$. Inspection of the raw data revealed that the direction of change was positive; that is, from more "problem behaviors" at Time 1 toward fewer "problem behaviors" at Time 2 since higher raw scores on the Adapted Walker indicate fewer problem behaviors.

Therefore it can be concluded that the first hypothesis was confirmed. "Problem behaviors" decreased between entrance into and termination from the program. Inspection of the raw scores further revealed that the behavior change noted is true for 31 of the 33 children tested. of the two remaining children, one showed no change and one showed an increase in problem behaviors.

As another method of examining the data, a change score was obtained by subtracting Time 1 from Time 2 raw scores on the Adapted Walker. The mean of the change scores was 34.61. Change scores between Time 1 and Time 2 appeared to be fairly evenly distributed between a low of 11 and a high of 62 with a slight skewing toward the top end of the scale. This distribution would indicate that the mean change was not heavily affected 
by the deviant scores of a few individuals.

Hypothesis 2, Stability of Behavior Changes After Treatment

In order to assess the longevity of treatment gains it was necessary to determine whether decreases in "problem behaviors" between entrance into and termination from the program were maintained subsequent to termination. This required gathering data at a point in time after the children in the study had been terminated from the program. As described in the previous chapter, these data were gathered by applying the same instrument used at Time 1 and Time 2 at the time of follow-up. (Time 3$)^{35}$

For 26 of the 33 children in this study, Time 3 data was gathered from both parents and teachers. Time 3 data for the remaining 7 children was provided by either a parent or a caretaker. Time 3 scores were then averaged for those children who received ratings from both parents and teachers. For the remaining children the single parent or caretaker score on the Adapted Walker was used in subsequent computations.

To determine whether teachers tended to rate children higher or lower than parents on the Adapted Walker, raw score means were computed for both groups. Also difference scores between the two ratings for each child were found and a mean of these scores between the two ratings were 163.3 and 162.5 respectively. Differences in ratings for individual children ranged from 2 to 71 with 7 children having a difference score of 5 or less and 6 children having a difference score of 40 or more. Comparison of the means of the raw scores for the two groups and examination of the difference scores indicates no tendency for one group to rate children either higher or lower on the Adapted Walker than the other. It was therefore assumed that averaging teachers and parents 
scores would not detract from the accuracy of the behavioral ratings at Time 3.

The significance of the difference between the means of Time 2 raw scores and Time 3 raw scores was tested by the use of a T-test. Further analysis of the data was done by inspection and by simple averaging. To confirm the hypothesis, a T-test should have indicated that there was no significant difference between the means of raw scores at Time 2 and Time 3. Using the Time 2 raw score mean of 175.97 and the Time 3 mean of 160.79 computation yielded $\mathrm{T}=3.24$ indicating a significant difference between the two sets of scores at the $P=.01$ level of confidence. Therefore the second hypothesis was not confirmed. Further inspection of the raw scores for Time 2 and Time 3 revealed that the difference was negative; that is, children tended to score significantly lower at followup than they did at termination. (See Appendix VI)

The mean change score between termination and follow-up for all children rated was -15.18 points as compared to the previously mentioned gain of 34.55 points between time of entry and time of termination.

\section{Behavior Change Between Entry and Follow-up}

Having discovered that positive behavior changes made during treatment decrease significantly during the period after treatment the researchers felt it would be important to assess the overall behavior change of the children studied; that is, the change in "problem behaviors" between Time 1 (entry) and Time 3 (follow-up). As before, a T-test, inspection, and simple averaging were used to analyze the data.

$T=3.73$ indicated that there was significant difference between Time 1 and Time 3 raw scores at the $P=.01$ level of confidence. Inspec- 
tion of the scores revealed that the mean change in raw scores between Time 1 and Time 3 was 19.36 and that the direction was positive. Therefore it was concluded that children demonstrated significantly fewer "problem behaviors" increased markedly between termination and follow-up. Thus there appears to be some loss of gains made during treatment after children were terminated. These losses however, do not eliminate overall treatment gains. Further inspection of the raw scores (See Appendix VI) supports this trend. One child scored lower at follow-up than at termination than at entry whereas twenty-four children scored lower at follow-up than at termination. Only eight children, however, scored lower at follow-up than at entry.

It is recognized that comparing Time 2 scores with Time 3 scores presents some obvious problems since the data for Time 2 comes from the treatment staff via case records whereas Time 3 data comes directly from parents, caretakers, and teachers, all of whom may have different perceptions of children's behavior. Implications of these possible discrepancies will be discussed in the following chapter. (See Appendix VI)

\section{BEHAVIOR CHANGE AND PARENT INVOLVEMENT}

Hypothesis 3, Parent Involvement and Behavior Change During Treatment

It was hypothesized that children whose parents demonstrated "high" involvement during day treatment would show higher "positive behavior change" during treatment than would children whose parents demonstrated "low" involvement in the Day Treatment Program. That is, high parent involvement during treatment would be associated with more of a tendency toward reduction in "problem behaviors" during that period than would "low" parent involvement. 
Use of the terms "negative behavior change" and "positive behavior change" as used in this and the following hypotheses implies the use of change scores instead of raw scores in statistical computations. As noted previously, change scores are changes in raw scores on the Adapted Walker between one test time and another.

The Parent Involvement. Scale (See Appendix I) for staff described in the methodology section was used to rate children's parents or parent surrogates as either high or low involvers for that period of time when their children were in treatment. Staff responses on the Parent Involvement Scale were simply tallied for each parent. If a family was rated as highly involved by more staff members than rated the family as low, the family was considered highly involved for the purposes of this part of the study. The degree of behavior change was derived by subtracting children's scores, on the Adapted Walker at Time 1 from their scores at Time 2. These change scores (See Appendix VI) were then categorized as high, medium, and low positive change. This was accomplished by labeling the eleven highest changers "high," the eleven lowest changers "low" and the remaining eleven "medium." "Parent involvement" and "behavior change" were then related by means of a $2 \times 3$ Chi Square as noted in Table III below. 
TABLE III

Parent Involvement During Treatment and Positive Behavior Change Between

Entry and Termination

\begin{tabular}{|c|c|c|c|c|}
\hline & $\begin{array}{l}\text { Low Positive } \\
\text { Behavior Change }\end{array}$ & $\begin{array}{l}\text { Medium Positive } \\
\text { Behavior Change }\end{array}$ & $\begin{array}{l}\text { High Positive } \\
\text { Behavior Change }\end{array}$ & Total \\
\hline $\begin{array}{l}\text { High Parent } \\
\text { Involvement }\end{array}$ & A & B & C & 15 \\
\hline $\begin{array}{l}\text { Low Parent } \\
\text { Involvement }\end{array}$ & D & $E$ & F & 18 \\
\hline Total & 11 & 11 & 11 & 33 \\
\hline
\end{tabular}

A computed Chi Square of 9.537 indicated a significant relationship between "parent involvement" and "behavior change" at the $\mathrm{P}=.01$ leve1 of confidence. Cell " $\mathrm{C}$ " from the table above indicating high positive change and high involvement reveals a distinct subgroup of nine children whereas only two children appeared in cell "F" representing those who showed high positive behavior change but low parent involvement. Conversely, only six of those children whose parents were rated as highly involved in treatment showed low to medium positive behavior change (ce1ls "A" and "B"). The largest grouping was the sixteen children who showed low to medium behavior change and whose parents were rated as low involvers. Thus, high parent involvement during treatment appears to result in greater positive behavior change during the course of a child's treatment whereas low parent involvement appears to result in less positive behavior change. 
Hypothesis 4, Parent Involvement During Day Treatment and Maintenance of Treatment Gains Between Termination and Follow-up

This hypothesis relates to the relationship between parent involvement during treatment and behavior change after treatment. It was predicted that the degree of parent involvement during the treatment period would be associated with the degree to which behavioral gains made during treatment were maintained after treatment. It was hypothesized that children whose parents demonstrated "high" involvement during day treatment would show greater "positive behavior change" or less "negative behavior change" after day treatment than would children whose parents demonstrated "low" involvement in the Day Treatment Program.

A $2 \times 3$ Chi Square was also used to test this hypothesis. The behavior change data were derived by subtracting children's raw scores on the Adapted Walker at Time 2 (termination) from their scores at Time 3 (follow-up). (See Appendix VI) The resulting change scores were then divided into three groups of 11. The 11 largest negative scores were designated "high negative change." The 9 positive scores and the 2 smallest negative scores were designated "positive change and low negative change." The remaining 11 scores were designated "medium negative change." Parent involvement data for the Chi Square computation are the same used in hypothesis 3. 
TABLE IV

Parent Involvement During Treatment and

Behavior Change Between Termination

and Follow-up

\begin{tabular}{|c|c|c|c|c|}
\hline & $\begin{array}{l}\text { Positive Change } \\
\text { and Low Negative } \\
\text { Change }\end{array}$ & $\begin{array}{l}\text { Medium Nega- } \\
\text { tive Change }\end{array}$ & $\begin{array}{l}\text { High Nega- } \\
\text { tive Change }\end{array}$ & Total \\
\hline $\begin{array}{l}\text { High Parent } \\
\text { Involvement }\end{array}$ & $\begin{array}{ll}\text { A } & 4 \\
\end{array}$ & $B$ & 6 & 15 \\
\hline $\begin{array}{l}\text { Low Parent } \\
\text { Involvement }\end{array}$ & $D$ & 6 & 5 & 18 \\
\hline Total & 11 & 11 & 11 & 33 \\
\hline
\end{tabular}

Interestingly, the cell count above indicates no easily discernable pattern of association between parent involvement during treatment and degree of behavior change between termination and follow-up. Computation yields a Chi Square of 1.134 and reveals that there is not a significant relationship between parent involvement.during treatment and stability of treatment gains after treatment at the $P=.05$ level. ${ }^{36}$ Thus this hypothesis was not confirmed.

Hypothesis 5, Parent Involvement After Treatment

The final prediction about parent involvement was that children whose parents tended to be more involved in their child's treatment or school program after the child's termination from the Day Treatment Center would have fewer behavior problems during that period than children whose parents tended to be less involved. It was hypothesized that children whose parents demonstrated "high" involvement in their children's school or treatment program after termination from day treatment would show greater "positive behavior change" or less "negative behavior 
change" after day treatment than would children whose parents demonstrated "low" involvement after treatment.

Behavior change data were derived by subtracting children's scores on the Adapted Walker at Time 2 from their scores at Time 3. (See Appendix VI) Data about parent involvement after day treatment came from Part I of the Primary Instrument. (See Appendix II) The method of deriving the parent involvement index from the questionnaire has been discussed previously in the methodology section. Essentially the procedure involved counting the frequency of parent contacts with a variety of treatment sources and assigning the parent an index score proportionate to the number of these contacts per month.

The relationship between the variables of parent involvement after treatment and behavior change after treatment was examined by the use of "T" employing the mean of the involvement index scores and the mean of the behavior change scores.

Computation using a mean of 2.777 on the parent involvement index scores and a mean of -15.18 on the change scores resulted in $\mathrm{T}=3.196$. This indicated that the relationship between parent involvement after treatment and behavior change as measured was significant at the $P=.01$ level. (See Appendix VIII) Thus, those children in the study whose parents tended to be more highly involved in their treatment after termination from day treatment were also the children who tended to maintain gains made during day treatment. Discussion regarding why parent involvement seems to reduce problem behaviors as predicted by this hypothesis and hypothesis 3 but tends not to confirm the prediction of hypothesis 4 will be discussed in the following chapter. 


\section{FAMILY DISRUPTION AND STABILITY OF BEHAVIOR CHANGE AFTER}

\section{TREATMENT}

In considering the relationship between family stress and maintenance of treatment gains it was predicted that the more family stress a child encountered after day treatment the less likely he would be to maintain gains made in treatment. It was hypothesized that children who experienced less "family stress" after day treatment would demonstrate greater "positive behavior change" or less "negative behavior change" after day treatment than would children who experienced more "family stress." Assuming that family disruption would be the primary cause of family stress the researchers thus measured "disruptive family changes" in Part II of the Primary Instrument. (See Appendix II)

The procedure for converting the data from Part II into a "stress factor" for each child has been discussed in the methodology section. Briefly stated, the procedure involved counting the number of family changes reported in Part II and dividing this number by the number of months that had passed since the child had been terminated from the Day Treatment Program. The resultant number multiplied by one hundred was called the "stress factor." (See Appendix IX)

To determine the significance of the relationship between "family stress" and negative behavior change, " $\mathrm{T}$ " was found using the means of the stress factor scores and the change scores. (See Appendix IX) $T=1.78$ indicated a probability of .119 that low "family stress" and negative behavior change were related by chance. Since this probability level is larger than $\mathrm{P}=.05$ it cannot be said that there is a significant relationship between these two variables as defined in this study. These results, however, suggest a tendency in the predicted 
direction. Some possible meanings of this finding and their implications will be discussed in the following chapter.

\section{ADDITIONAL FINDINGS}

Diagnostic Category and Behavior Change

Since the literature refers frequently to varying prognoses for children falling into various diagnostic categories, the researchers felt that it would be interesting to relate behavior change as measured by the Adapted Walker to the main diagnostic categories used by the Day Treatment Center. To do this, the primary diagnostic labels applied to each of the children at the time of their entrance into the Day Treatment Program were used. Then the "mean change score" for the children in each of the categories was computed by subtracting each child's score on the Adapted Walker at Time 1 (entry) from his score at Time 3 (followup) and averaging the scores in each group. The entry to follow-up time period was used as opposed to the entry to termination period in order to assess change over maximum time and most varied conditions.

TABLE V

DIAGNOSTIC CATEGORY AT ENTRY

AND BEHAVIOR CHANGE BETWEEN

ENTRY AND FOLLOW-UP

\begin{tabular}{l|c|c}
\hline \multicolumn{1}{|c|}{ Diagnostic Category } & $\mathrm{N}$ & Mean Change Score \\
\hline & 2 & 18.25 \\
Organic Brain Syndrome & 2 & 10 \\
Mental Retardation & 8 & 29 \\
Situational Disturbance & 14 & 21.64 \\
Behavior Disorder & 1 & 21 \\
Neurosis & 6 & 4.42 \\
Non-Organic Psychosis & 33 & $\overline{\mathrm{x}}=19.36$ \\
\hline
\end{tabular}


The eight children with situational disturbances involving primarily childhood adjustment reactions appeared to show the most improvement on the Adapted Walker. Interestingly, children with organic difficulties which usually included related emotional problems fared nearly as well as those with behavior disorders. Mentally retarded children made relatively small gains.

The category designated "non-organic psychosis" included children whose psychotic behavior could not be directly attributed to physiological causes. Children labeled autistic and schizophrenic were included in this group. The change score of 4.42 for this group indicates significantly fewer overall treatment gains than for the other categories. $^{37}$ The lowest change scores for the children in this group were also the lowest change scores in the study population.

Behavior Change and Length of Time Between Termination and Follow-up

Table VI relates the length of time between termination and followup for the children studied to mean changes in scores on the Adapted Walker between these two times.

TABLE VI

BEHAVIOR CHANGE BETWEEN TERMINATION

AND FOLLOW-UP AND NUMBER OF

MONTHS SINCE TERMINATION

\begin{tabular}{r|c|c}
\hline $\begin{array}{l}\text { Months Since } \\
\text { Termination }\end{array}$ & $\mathrm{N}$ & Mean Change Score \\
\hline $0-12$ & 10 & -18.95 \\
$13-24$ & 12 & -13.96 \\
$25-36$ & 11 & -13.09 \\
\hline Tota1 & 33 & \\
\hline
\end{tabular}


The negative mean change scores indicate that all three groups of children continue to experience deterioration of gains made during treatment up to thirty-six months after termination. This deterioration appears to be greatest for children who have been out of the program less than one year as indicated by a mean change score of -18.95. Children who have been out of the program for more than one year appear to show less deterioration. Implications of this finding will be discussed in the following chapter. 


\section{CHAPTER VI}

\section{DISCUSSION AND CONCLUSIONS}

One purpose of the study was to measure the incidence of problem behaviors in specific children during and subsequent to their involvement in the Child Psychiatric Day Treatment Program. A second purpose was to assess the stability of behavior changes in terms of the number and the frequency of problem behaviors after these children left the program. Last of all, two independent variables which may have affected the number and frequency of problem behaviors were examined. These two variables were parent involvement and family stress.

In an attempt to get an overall picture of this process, problem behaviors were measured at three points in time: time of entry into the program (Time 1), time of termination from the program (Time 2), and time of follow-up (Time 3). Behavior change was calculated by determining changes in the incidences of problem behaviors between these time periods. Parent involvement was examined during treatment and again, following treatment. Family stress was measured between termination and follow-up.

Following this introduction are the discussions, implications and conclusions drawn from the findings. Finally, a summary is included at the end of this chapter. 


\section{DISCUSSION OF PRINCIPAL FINDINGS}

As discussed in Chapter $V$, the data clearly support the association of treatment and positive behavior change among children during the treatment period assuming the validity of the instruments and the accuracy of the information used. This finding is based on the reduction in "problem behaviors" among these children between entry and termination from the Day Treatment Program.

As noted in the literature review, Baumann (1975) and to a lesser extent, Hyman (1973) found that day treatment resulted in positive behavior change among emotionally disturbed children. This is consistent with the results obtained in the present study.

The researchers note several areas of caution. First, some variables were incompletely controlled. These include environmental and familial changes. For other confounding variables such as maturation of the subjects, there was no control. To account for these and other influences, the researchers suggest the employment of a comparison or control group. The use of such a group would reduce the possibility that something other than treatment was contributing to the child's improvement.

The second area of caution recognized by the researchers is the source of information (the child's treatment record) used to measure the occurrence of "problem behaviors" between entrance and termination from the Day Treatment Program. Since the day treatment therapist has energies invested in the improvement of the child, there exists the possibility that the child's record is biased to some extent. That is, the record reflects the thinking of the therapist who has a vested 
interest in the treated child, and she or he may wish to communicate in the treatment record that the child is functioning better at termination than at entry to legitimatize the treatment program as well as his or her role as therapist. Therefore, the researchers strongly suggest that the Adapted Walker be completed at the time of entrance into the program and at termination by one individual utilizing observation rather than relying upon the child's treatment record for information regarding the effects of treatment.

With the noted limitations, the result implies that there is some degree of positive behavior change in children involved in the Day Treatment Program.

Contrary to the prediction of the second hypothesis, the level of behavioral improvement achieved at termination was not maintained at the time of follow-up. The result suggests that some degree of deterioration in the child's behavior occurred between termination and follow-up although there is generally not a return to the level of dysfunctional behavior operant at the time of entry into the program. This result suggests that some gains are lost.

These losses may have occurred for several reasons. First, the child is placed in a new environment, usually a public school, following termination from the Day Treatment Center. This new setting will have new rules, norms, and limitations which may demand higher standards of behavior. Various learned or expected responses in day treatment may now be ignored or dealt with differently in the new environment. Thus, the change in environment may induce some regression in the child's behavior following termination from the Day Treatment Program. 
As the child eventually adapts to the new environment, improvement in his or her functioning may follow. This may account for the results (See Table VI) which indicate that the longer the time-span between termination and follow-up, the higher the degree of maintenance of treatment gains.

Secondly, the family and child lose a major support system at termination. Feelings of loss, fear, depression and other related anxieties may contribute to the child's regression. This implies that in order for treatment gains to be maintained, the program must offer a strong and supportive follow-up component. In addition, many children may continue to need some sort of treatment following day treatment. Some procdures used in the collection of data may also have influenced the results. Of major importance are the different raters, various methods and times of data collection and various sources of information used in the completion of the Adapted Walker. As previously described, the researchers rated each child at times of entry and termination using documented information from the child's treatment record. Parents, caretakers, and teachers used personal day to day contact and observation in completing the Adapted Walker at the time of follow-up. The comparison of the various ratings might therefore be subject to error due to the variation in the raters and in sources from which information was drawn to complete the Adapted Walker. Therefore, it is suggested that in subsequent research that one rater be used consistently to measure behavior at the three points in time. Furthermore, the use of daily observation for completing the Adapted Walker is highly recommended to reduce the noted sources of error. 
The researchers might have been less severe in their ratings than teachers, caretakers, and parents since their theoretical background and interests lay in the areas of personality and emotional growth and development. Furthermore, as discussed earlier, the treatment records may contain some degree of bias due to the therapists' vested interest in the child's positive behavioral gains. In addition, they may have been more tolerant of "problem behaviors" than teachers, caretakers, and parents who may concentrate on behavioral management and therefore demand higher standards of behavior. Thus, parents, caretakers, and teachers may have been more severe in their ratings on the Adapted Walker.

Outside factors may have further contributed to the behavioral deterioration of some of the program children. One such variable, family stress, was measured. A slight trend indicating the significance of the influence of family stress on the stability of behavior change was noted in the findings. This is discussed in greater detail in this chapter.

On the whole, the result indicates that problem behaviors diminish between time of entry and time of follow-up. The data show that in all but eight cases, children showed some positive improvement in behavior. This result suggests that even though children tended to lose gains between termination and follow-up, the overall effect between entry and follow-up was positive. This is, behavior change does appear to result from therapeutic intervention with the parent and child.

These findings are very important to the field of social work. Today, when the utility of treatment is being questioned, such results suggest its importance. The results support both the short term and long term effectiveness of treatment. 
The researchers recognized that the population studied between termination and follow-up may be somewhat distorted. That is, 6 children living in residential treatment centers were included in the sample population and these treatment centers were regarded as the child's "family." The literature review pointedly notes the importance of the family in the treatment of the child. These two groups were, however, treated as one population. An alternative instrument (See Appendix III) was designed to compensate for this difference which accounted for essentially the same variables as were measured in the primary instrument. Subsequent research might divide these groups into children in residential treatment centers and those living in families, and statistically evaluate differences between these two groups.

Examination of the data relating to behavior change and parent involvement suggest that a highly significant relationship exists between these two variables. This is consistent with the results of other studies. (Wolff, 1969; Lansing, 1967; Bridgeland, 1971; and Green, 1972) These authors note that parental involvement is a very important component for treatment success of emotionally disturbed children.

As noted in Chapter $V$, those children designated as low positive changers during treatment tended to have parents who were minimumly involved in the Day Treatment Program, whereas high positive changers tended to have highly involved parents. It is interesting to note in Table III that medium changers tended to have parents judged as low involvers. One might speculate from these results that without high parental involvement, a child can benefit from day treatment up to a certain point, that is to medium positive behavior change. However, in order to achieve maximum behavioral change, high parental involvement 
may be a necessary factor.

These findings must be qualified by the possibility that the Parent Involvement Scale was an inaccurate measure of parental involvement. Involvement was based on the subjective judgements of Day Treatment staff who relied on memory in the completion of the Scale. This method of measuring involvement may have been less objective than documented records, which would have been used had they been consistently available. Future research might take this factor into account.

Parent involvement during treatment seems to have little effect on the maintenance of behavior gains according to the findings. The data show no easily discernable pattern of association between parent involvement during treatment and the degree of behavior change between termination and follow-up.

The failure of the data to support this hypothesis may be attributable to problems with the parent involvement measure. The weaknesses of the Parent Involvement Scale have already been discussed. As noted earlier, a test relying on actual behavior might better judge the degree of parental involvement.

As noted earlier, regression following treatment seems to be predictable. Several measures might be implemented in order to limit the amount of regression and increase the carry-over effect of parent involvement during treatment. Such measures might include the re-construction of a Follow-up Team. This team would offer support, information, and "treatment" to the child and family. For instance, in the school, where a majority of these children are placed following day treatment, such a Team might act as consultant to school personnel. 
In addition, in any treatment effort following day treatment, parent involvement should be strongly emphasized in order to reduce the loss of behavior gains. This would include involvement in the school classroom. Regular parent-teacher conferences, classroom observation and participation by the parents and parent meetings might be possible modes of involvement in the school. Such efforts might reduce the noted regression in behavior and help maintain the positive behavior changes.

- The findings suggest that parental involvement following day treatment and the maintenance of behavior gains are significantly related. Parents who continue to be involved in their children's treatment tend to have children who maintain behavioral gains. This lends support to the assumption that in any therapeutic process, parental involvement is necessary for successful treatment. As discussed earlier, the findings suggest that parental involvement during treatment was significantly related to positive behavior change at termination. The instruments measuring parent involvement vary however, in the two cases noted.

In contrast to the method of assessing parental involvement during treatment, the instrument used at follow-up to measure parental involvement was based on parent or caretaker reported behavior. The basis for determining high or low involvement was the frequency per month of parent contacts with the treatment agent. All contacts were given equal weight so that a parent receiving daily phone contacts with the treatment agent would receive weight equal to a parent engaged in daily face to face contact with the treatment agent.

In future research it might be important to devise a method of determining the impact that various forms of parent contact have on childrens' success in treatment. Also, it might be important to determine 
the types of childrens' problems that parent involvement impacts most significantly. In some cases, parent involvement after treatment may be minimal if these children are not having obvious problems. The absence of parent involvement in these cases, may have unknown long term effects.

The data suggest a relationship between stability of behavior change and family stress. This relationship however, is not significant at the $\mathrm{P}=.05$ level of confidence. The literature strongly supports the notion that family stress produces and results in emotional disturbances in children and adults. (Wolff, 1969; Holmes, 1971; Laszarus, 1966; and Tanner, 1960)

The failure of data to fully support the hypothesis may be attributable to a number of factors. The Family Stress Schedule may not adequately measure the family stress level. The Schedule treats al1 changes or stresses equally regardless of the intensity or severity of the effect it may have had on the family and children. So what may have been a serious change in one family might have been weighted equally to a similar but a less significant change in another family. In addition, some stress agents were not included as elements of stress, such as the death of a child's dog. According to the child's mother, this greatly upset the child. It is conceivable that a broad range of related yet unaccounted for "stressers" such as the death of the dog, may have impacted the child's adjustment. Therefore, the Schedule may not have accurately measured family stress.

Several implications can be drawn from this result. First, the result suggests the need for further study in the area of family stress. In order to evaluate factors affecting the stability of treatment gains 
made during treatment, the importance of specific stress agents and the development of a reliable and valid instrument measuring family stress are suggested. Secondly, there is a need for family support systems following day treatment, not only to aid in the maintenance of behavior gains, but to assist those families experiencing stress. This need is not confined to this group of individuals alone. Long waiting lists in public and private agencies offering social services suggest the inadequate number of support systems in the larger community. The development of such community resources is highly recommended.

\section{DISCUSSION OF ADDITIONAL FINDINGS}

Behavior Change by Diagnostic Category

As noted previously "behavior change" was related to diagnostic category in order to determine which categories of children appeared to show the most improvement between entry and follow-up. The findings indicated that those categories for which the generally accepted prognosis was most positive were also the categories which showed the greatest improvement by the methods used in this study. Those categories with the least favorable prognoses tended to show the least improvement in this study.

If the initial psychiatric diagnoses and prognoses for the children in this study were accurate, then the degree of consistency between these predictions and the study findings tends to support the validity of the Adapted Walker as an instrument for measuring behavior change.

Situational Disturbances. As indicated in the previous chapter, children with situational disturbances appeared to show the greatest positive behavior change among the six diagnostic categories considered. 
This finding is understandable if the inftial diagnoses were correct. Presumably children with situational disturbances have difficulty in adjusting either to their environment or to their own development. Subsequent environmental changes or continued maturation are factors not necessarily related to treatment which may result in improvement among these children. That is, whether or not treatment results in improvement in this group.

As with all children in this study, but certainly with this group, further research is needed to isolate the effects of treatment. Randomization and use of a control group could produce more definitive results.

Behavior Disorders. The group of children initially diagnosed as having behavior disorders showed less "positive behavior change" than the group of children with more transient problems but more positive change than the children in the remaining diagnostic groups. This also is consistent with diagnostic predictions. Although the behavioral manifestations associated with this diagnosis are presumed to be reactive, they also appear to be less likely to change. ${ }^{38}$ The fact that these children demonstrated significant positive behavior change during treatment and maintenance of change after treatment to some extent, would support the likelihood of positive treatment effects.

Organic Problems and Mental Retardation. Although the number of children treated for organic brain syndrome and mental retardation was sma11, the relative treatment gains of these two groups as indicated by their change scores is rather surprising. Children with organic brain syndrome showed positive change scores nearly as high as children with behavior disorders. Both organic brain syndrome and mental retarda- 
tion groups showed higher change scores than children diagnosed as psychotic.

These results would indicate that children in these categories should not necessarily be excluded from psychiatric day treatment programs because of their limited capacities for change. For children with organic brain syndrome, the early distinction between chronic and acute could help in making this decision. For children diagnosed as mentally retarded, the condition is, by definition, chronic. There are indications, however, that this diagnosis is sometimes confused with other more transient conditions. 39

Psychoses. As noted in the findings section the group of children with primary initial diagnoses of psychosis showed by far the smallest positive behavior change. The literature suggests that the earlier the onset the worse the prognosis for the autistic and schizophrenic children in this group. ${ }^{40}$ Thus, guarded prognoses could be expected for such children the age of those in the study population. Half of the children in this group actually showed negative behavior change between entry and follow-up.

It should be pointed out however that the mean positive change score for this group during treatment was only slightly below the mean for all children in this study; 34.0 and 34.57 respectively. The most rapid behavioral deterioration seemed to occur between termination and follow-up. During this period, the mean negative change score for this group was 1.7 times larger than the mean negative change for all children in the study; -25.9 and -15.18 respectively.

The implications of these results are two-fold. First, involvement in the Day Treatment Program appears to have had significant 
positive effects for some psychotic children and these positive effects are typically not anticipated in the literature. This type of program may be as helpful to these children as a residential program. Intake screening should not necessarily eliminate such children from day treatment programs because of poor prognosis, at least not on the basis of these findings. Further research might help to determine which program inputs have positive effects and which psychotic children are most ameanable to those inputs.

Secondly, the post treatment period for these children appears to be critical. Either because of divergent expectations by caretakers or because of actual changes among the children, psychotic children show marked behavioral deterioration after treatment compared to other diagnostic groups. This indicates that follow-up efforts may need to be intensified for these children either by sustaining the therapeutic aspects of the treatment program or by helping the new caretakers to better accept the behaviors and behavioral improvements of these children. Change may be more devastating to psychotic children.

The tendency for all diagnostic groups to show improvement during treatment and some degree of deterioration afterward would support the previously mentioned suggestion in support of increased follow-up efforts. The need for more intensive follow-up is, however, more dramatically stated by the group of children designated as psychotic than by the other groups.

Behavior Change and Length of Time Since Termination From Day Treatment When change scores between entry and follow-up were grouped according to the number of years since children had been terminated from the 
Day Treatment Program, it was found that all groups showed negative behavior change. Children who had been terminated one year or less previous to the time of follow-up, however, showed considerably higher negative behavior change than did children who had been out of the program for longer periods of time.

This might imply that the benefits of treatment are not realized until long after termination. Children on leaving the program show rapid behavioral deterioration and it is only after considerable time has passed that they begin to regain some positive changes which were made during treatment.

As noted previously, the regression effect may be caused by adjustment difficulties among the children leaving the program and also among their caretakers. Considerable time may be required for children to adjust to expectations different from those at the Day Treatment Center and for teachers or caretakers to adjust their expectations to the performance capacities of the children involved.

Also, possible effects of program changes at the Day Treatment Center should be considered. Since there has been staff reorganization during the past three years it is possible that the previous follow-up arrangement was simply more successful in facilitating maintenance of treatment gains than the present arrangement.

\section{SUMMARY}

This study has undertaken:

1) To construct, an instrument capable of accurately examining behavior changes among a population of emotionally disturbed children over a period of several years. 
2) To develop other instrumentation capable of assessing variations in the degrees of parent involvement and family stress operant among the children studied.

3) To develop a design which will allow examination of the relationship between behavior change and the independent variables of parental involvement and family stress.

4) To examine behavior changes in terms of treatment gains and the maintenance of these gains after treatment in interaction with the independent variables within the context of a particular treatment setting.

In summary, this study has produced an instrument, the Adapted Walker, which the authors feel has sufficient reliability and validity to be of use in further research assessing behavior change among emotionally disturbed children. The other instrumentation in this study, however, is of more questionable value and may require considerable refinement.

The principal findings, given the qualifications of inexact instrumentation and unrefined methodology, do seem to suggest some important relationships:

1) The children in this study appeared to make statistically significant therapeutic gains during treatment but experienced considerable deterioration of these gains following termination from treatment.

2) Children whose parents were assessed as highly involved during treatment appeared to improve more during treatment than children whose parents were less involved.

3) Parent involvement during treatment appeared to have negligible residual effect on the maintenance of treatment gains following termination. There was no statistically significant behavioral difference after 
treatment between children whose parents were highly or minimally involved during day treatment.

4) The post-treatment relationship between family stress as measured in this study and the maintenance of treatment gains appears to be tenuous. Children who experienced more family stress after treatment tended to show more behavioral deterioration than those who experienced less stress but the relationship between stress and negative behavior change was not found to be statistically significant.

5) Some additional findings suggest that:

a) Behavior change as measured by the Adapted Walker is fairly consistent with that which would be predicted by children's psychiatric diagnoses at intake.

b) As rated by the Adapted Walker, children who have been terminated from the Day Treatment Program for less than one year appear to have more behavioral difficulties than children who have been out longer. 
FOOTNOTES

CHAPTER II

1 James K. Whittaker, "The Ecology of Child Treatment; A Developmental/Educational Approach to the Therapeutic Milieu," Journal of Autism and Childhood Schizophrenia, vol. 5, no. 3. (1975), pp. 223-237.

2 James K. Whittaker, "The Child Care Continuum, New Directions for Children's Residential Centers," Child Care Quarterly, vol. 2, no. 2, (1973), pp. 124-135.

3 Clark E. Mustakas and Minnie Perrin Berson, The Nursery School and Child Care Center, (New York, William Morrow \& Co., 1955).

4 Mental Health Division, Oregon State Board of Control, Pilot Program for Emotionally Distrubed Children in Oregon, (Salem, Or., Mental Health Division, Board of Control, 1969), p. 1.

5 Eugene E. Taylor, Needed Services for Emotionally Disturbed Children in Oregon, (Oregon Mental Health Planning Board, 1965), pp. 1-5.

6 Louise J. Desport, The Emotionally Disturbed Child, (Garden City, New York, Doubleday \& Co., 1970), pp. 145-227.

7 David Maclay, Treatment for Children, (New York, Science House, Inc., 1970), pp. 19-31.

8 Richard A. Gardner, Understanding Children, (New York, Jason Aronson, Inc., 1969), p. 230 .

9 Thomas H. Holmes, Minora Maswda, and Allen R. Wyler, "Magnitude of Life Events and Seriousness of Illness," Psychosomatic Medicine, vol. 33, no. 2, (1971), pp. 115-121.

10 Richard S. Lazarus, Psychological Stress and the Coping Process, (New York, McGraw-Hil1, 1966), pp. 150-312. 
11 J. M. Tanner, ed., Stress and Psychiatric Disorder, (Oxford, Blackwell Scientific Publications, 1960), pp. 13-49.

12 Gilbert Kiliman, Psychological Emergencies of Childhood, (New York, Gruney Stratton, 1968), pp. 13-110.

13 Sula Wolff, Children Under Stress, (Plymouth, England, The Bowering Press, 1969), pp. 51-171.

14 Ibid., p. 215 .

15 Barbara Green, "The Therapeutic Nursery Schoo1," Smith College Studies in Social Work, vol. 43, no. 1, (1972), pp. 49-50.

16 Maurice Bridgeland, Pioneer Work With Maladjusted Children, (London, Staples Press, 1971).

17 Cornelius Lansing and Eric Schapler, Group Psychotherapy of Preschool Psychotic Children, (Final Report, National Institute of Mental Health Grant, no. 14756, 1967).

18 Ralph P. Truitt, The Child Guidance Clinic and the Community, (New York, Commonwealth Fund, 1928), pp. 11-12.

19 Richard L. Blanton, "Historical Perspectives on Classification of Mental Retardation," in Issues in the Classification of Children, ed. Nicholas Hebbs, (San Fransisco, Jossey-Bass Publishers, 1975), p. 9.

20 Darold Treffert et al., "An Inpatient Treatment Program and Outcome for Fifty-Seven Autistic and Schizophrenic Children," Journal of Autism and Childhood Schizophrenia, vol. 3, no. 2, (1973), pp. 138-153.

21 Martin Kohn and Bernice Rosman, "Therapeutic Intervention and Disturbed Children in Day Care: Implications of the Deprivation Hypothesis," Child Care Quarterly, vol. 1, no. 1, (1974), pp. 21-45.

22 Evelyn Bauman, "A Day Treatment Program for Severely Disturbed Young Children," Hospital and Community Psychiatry, vol. 27, no. 3, (1976), pp. 174-179. 
23 Milton H. Hyman, "Efficacy of Day Treatment Intervention: Comparison of Two Matched Emotionally Distrubed Kindergarten Age Groups," Dissertation Abstracts International, vo1. 34, (Dec. 1973), p. 3190.

24 Robert A. Furman and Anny Katan, The Therapeutic Nursery Schoo1, (New York, International Universities Press, Inc., 1969), p. 230.

25 Paul Duke, et al., "A Descriptive Follow-up of Twenty-One Children from Parry Center," (M.S.W. Thesis, Portland State University, 1973).

26 James E. Johnston and Karen Shilling, "Assessment of Short Term Behavioral Changes in Emotionally Handicapped Children Enrolled in a Special Education Program," (M.S.W. Thesis, Portland State University, 1975).

27 Hill M. Walker, Walker Problem Behavior Identification Check1ist, (Los Angeles, Western Psychological Services, 1970).

CHAPTER III

28 "Program Review, December 1976," (Portland, OR, Children's Psychiatric Day Treatment Center, 1976).

CHAPTER IV

29 Hill M. Walker, Walker Problem Behavior Checklist Manual, (Los Angeles, Western Psychological Services, 1970), p. 1.

30 Ibid.

31 Ibid.

32 Hill M. Walker, Walker Problem Behavior Checklist, (Los Angeles, Western Psychological Services, 1970), p. 1

33

Claire Sellitz, Research Methods in Social Relations, (New York, Holt, Rinehart and Winston, 1959), p. 368. 
CHAPTER V

34 Sanford M. Dornbusch and Calvin F. Schmid, A Primer of Social Statistics, (New York, McGraw-Hill, 1959) p. 157.

35 Recognizing that for Time 1 and Time 2, information was taken from case records while Time 3 information was elicited directly from parents and teachers, it is unknown what effect sampling procedure has on the respective scores children receive on the Adapted Walker.

36 originally a $2 \times 2 \mathrm{Chi}^{2}$ had been computed to test this hypothesis $\mathrm{Chi}^{2}=.0000136$ indicating no significant relationship between the variables at any meaningful level of confidence.

37 On intake, the children in this group were diagnosed as either severely or moderately psychotic. The range of change scores we computed for these children ran from +42 to -37 thus indicating variation in treatment scores consistent with the "moderate" to "severe" designation.

\section{CHAPTER VI}

38

Committee on Nomenclature and Statistics of the American Psychiatric Association, Diagnostic and Statistical Manual of Mental Disorders, (Washington, D. C., American Psychiatric Association, 1968) p. 50 .

39

Ibid., p. 14-23.

40 Treffert, pp. 138-153. 


\section{A SELECTED BIBLIOGRAPHY}

Baumann, Evelyn, "A Day Treatment Program for Severely Disturbed Young Children," Hospital and Community Psychiatry, vo1. 27, no. 3, (1976), pp. 174-179.

Behar, Lenore and Stringfield, Samuel, "A Behavior Rating Scale for the Preschool Child," Developmental Psychology, vol. 10, no. 5, (1974), pp. 601-610.

Blanton, Richard L., "Historical Perspectives on Classification of Mental Retardation," in Issues in the Classification of Children. Edited by Nicholas Hobbs. San Fransisco, Jossey-Bass Publishers, 1975.

Blehar, Mary Curtis, "Anxious Attachment and Defensive Reactions Associated With Day Care," Child Development, vo1. 45, no. 3, (1974), pp. 683-692.

Bridgeland, Maurice, Pioneer Work With Maladjusted Children, London, Staples Press, 1971.

Browne, Thomas Henry, "A Study of Selected Psychological, Sociological, and Academic Factors Among Emotionally Disturbed Children in Three Treatment Programs," Dissertation Abstracts International, vo1. 36 (July-August, 1975), p, 215.

Committeee on Nomenclature and Statistics of the American Psychiatric Association, Diagnostic and Statistical Manual of Mental Disorders, Washington, D. C., American Psychiatric Association, 1968.

Despert, Louise J., The Emotionally Disturbed Child, Garden City, N. Y., Doubleday \& Co., 1970.

Dernbusch, Sanford M. and Schmid, Calvin F., A Primer of Social Statistics, New York, McGraw-Hi11, 1955.

Duke, et a1., A Descriptive Follow-up of Twenty-One Children From Parry Center, (An unpublished Master's Thesis), School of Social Work, Portland State University, 1973.

Furman, Robert A., and Katan, Anny, The Therapeutic Nursery School, New York, International Universities Press, Inc., 1969, p. 230.

Gardner, Richard A., Understanding Children, New York, Jason Anonson Inc., 1973, p. 31-84. 
Gartner, Dorothy and Goldstein, Harris S., "Some Characteristics of Mothers of Severely Disturbed Children in a Therapeutic Nursery," Psychological Reports, vol. 30, no. 3, (1972), pp. 901-902.

Gratten, Laurent and Rizzo, Adolfo, E., "Group Therapy With Young Psychiatric Children," International Journal of Group Psychotherapy, vo1. 19, no. 1, (1969), pp. 63-71.

Green, Barbara, "The Therapeutic Nursery School," Smith College Studies in Social Work, vol. 43, no. 1, (1972), pp. 49-50.

Holmes, Thomes H.; Masuda, Minoru; and Wyler, Allen R., "Magnitude of Life Events and Seriousness of Illness," Psychosomatic Medicine, vo1. 33, no. 2, (1971), pp. 115-121.

Hyman, Milton H., "Efficacy of Day Treatment Intervention: Comparison of Two Matched Emotionally Disturbed Kindergarten Age Groups," Dissertation Abstracts International, vol. 34, (Dec. 1973), p. 3190 .

Johnston, James E. and Shilling, Karen, Assessment of Short Term Behavioral Changes in Emotionally Handicapped Children Enrolled in a Special Education Program, (An unpublished Master's Thesis), School of Social Work, Portland State University, 1975.

Kiliman, Gilbert, Psychological Emergencies of Childhood, New York, Grune \& Stratton, 1968, pp. 13-110.

Kohn, Martin and Rosman, Bernice, "Therapeutic Intervention and Disturbed Children in Day Care: Implications of the Deprivation Hypothesis," Child Care Quarterly, vol. I, no. 1, (1974), pp. $21-45$.

Lansing, Cornelius and Schapler, Eric, Group Psychotherapy of Preschool Psychotic Children, Final Report, National Institute of Mental Health Grant, no. 14756, 1976.

Lappin, Raymond M. et al., Effects of Parenting Relationships on Children's School Adjustment, (An unpublished Master's Thesis), School of Social Work, Portland State University, 1976.

Love, Lenore R., et al., "Differential Effectiveness of Three Clinical Interventions for Different Socioeconomic Groupings," Journal of Counseling and Clinical Psychology, vol. 39, no. 3, (1972), pp. 347-360.

Lazarus, Richard S., Psychological Stress and the Capital Process, New York, McGraw-Hi11, 1966, pp. 50-312.

Maclay, David, Treatment for Children, New York, Science House, Inc., 1970, pp. 19-31. 
Marrane, R. Thomas and Anderson, Nancy, "Inactive Public School Programming for Emotionally Disturbed Children," American Journal of Orthopsychiatry, vol. 40, no. 4, (1970), pp. 694-701.

McAdoo, William G., and Roeske, Nancy A., "A Comparison of Defecters and Continuers in a Child Guidance Clinic," Journal of Consulting and Clinical Psychology, vol. 40, no. 2, (1973), pp. 328-334.

Mental Health Division, Oregon State Board of Control, Pilot Program for Emotionally Disturbed Children in Oregon, Mental Health Division, Board of Control, 2570 Center St. N.E., Salem, OR, 1969 , p. 1 .

Moustakas, Clark, E. and Berson, Minnie Perrin, The Nursery School and Child Care Center, New York, William Morrow \& Co., 1955.

Parents of Psychotic Children," British Medical Journal, vol. 4, no. 5837, (Oct.-Dec. 1972), pp. 379-380.

Program Review, December 1976, (An unpublished report), Children's Psychiatric Day Treatment Center, Portland, OR, 1976.

Schorr, Alvin L., Ed., Children and Decent People, New York, Basic Books, Inc., 1974, pp. 53-113.

Sellitz, Claine, et al., Research Methods in Social Relations, New York, Holt, Rinehart, and Winston, 1959, p. 368.

Slavson, S. R., Child Psychotherapy, New York, Columbia University Press, 1952 , p. 233 .

Spurkland, Virginia, et al., A Descriptive Study of Five Child Day Treatment Centers, (An unpublished Master's Thesis), School of Social Work, Portland State University, 1975.

Tanner, J. M., Ed., Stress and Psychiatric Disorder, Oxford, Blackwell Scientific Publications, 1960, pp. 13-49.

Taylor, Eugene E., Needed Services for Severely Emotionally Disturbed Children in Oregon, Oregon Mental Health Planning Board, 1965, p. 1 .

Treffert, Darold, et al., "An Inpatient Treatment Program and Outcome for Fifty-Seven Autistic and Schizophrenic Children," Journal of Autism and Childhood Schizophrenia, vol. 3, no. 2, (1973), pp. 138-153.

Treischman, Albert E., et al., The Other Twenty-Three Hours, Chicago, Aldine Publishing Co., 1969.

Truitt, Ralph P., Ed., The Child Guidance Clinic and the Community, New York, Commonwealth Fund, 1928, pp. 11-12. 
Tustin, Frances, Autism and Childhood Psychosis, New York, Science House, Inc., 1972, pp. 106-128.

University of Oregon Health Sciences Center, Children's Psychiatric Day Treatment Center, Plan for Clinical Services, (An unpublished statement), December, 1976.

Walker, Hill M., Walker Problem Identification Checklist, Los Angeles, Western Psychological Services, 1970.

Walker, Hill M., Walker Problem Behavior Identification Checklist Manual, Los Angeles, Western Psychological Services, 1970.

Whittaker, James, K., "The Child Care Continuum, New Directions for Children's Residential Centers," Child Care Quarterly, vol. 212, (1973), pp. 124-135.

Whittaker, James, K., "The Ecology of Child Treatment; A Developmental/ Educational Approach to the Therapeutic Milieu," Journal of Autism and Childhood Schizophrenia, vol. 5, no. 3, (1975), pp. 223-237.

Wolff, Sula, Children Under Stress, Plymouth, England, The Bowering Press, 1969, pp. 51-171. 


\section{APPENDIX I}

\section{Parent Involvement Scale}


This scale is designed to measure the degree of parents' involvement in the treatment program at the Children's Psychiatric Day Treatment Center while their child was in the milieu component. Attached is a separate sheet with the childrens' names, their time of entrance into and termination from the program, and a code number. According to the following considerations, please rate the degree of parental involvement for all children listed as either "high", "low", or "not applicable".

1. Consider the different ways that parents relate to the program (phone calls, management meetings, individual sessions, classroom visits, etc.).

2. Consider how often parents used these means of being involved with the program (missed appointments, unavailability, unwilling to participate in certain modes of treatment).

3. Consider parents' ability or willingness to make use of the different types of involvement (whether they were active or passive during contacts, whether contacts seemed productive or non-productive).

4. Since children are in the program for a number of months and in some cases, years; try to arrive at an average of the above considerations for the entire length of a child's stay.

5. If children have been placed outside their homes for a significant period during their stay, consider the involvement of the surrogate parents. 
CHILD

ENTRANCE TERMINATION

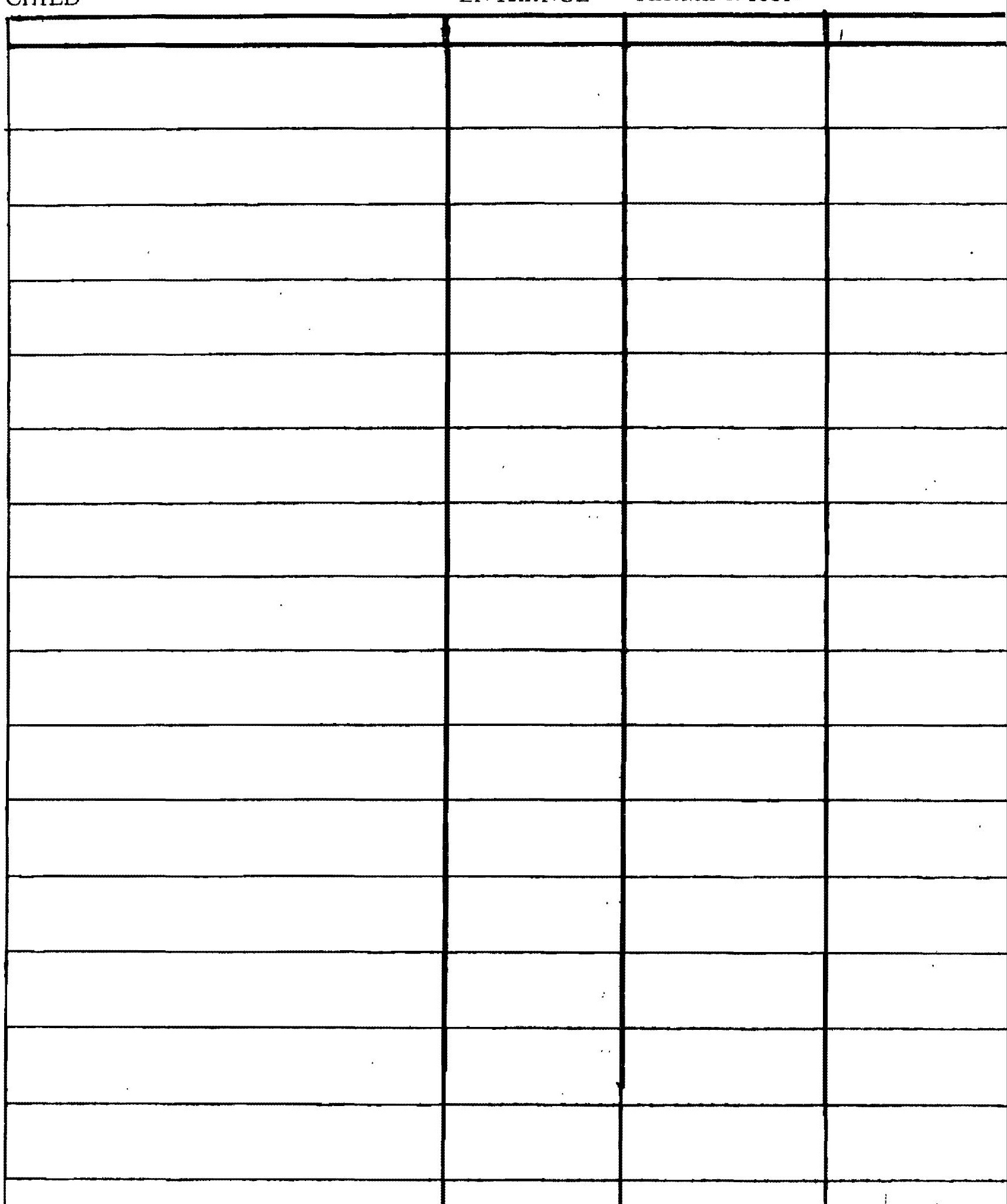




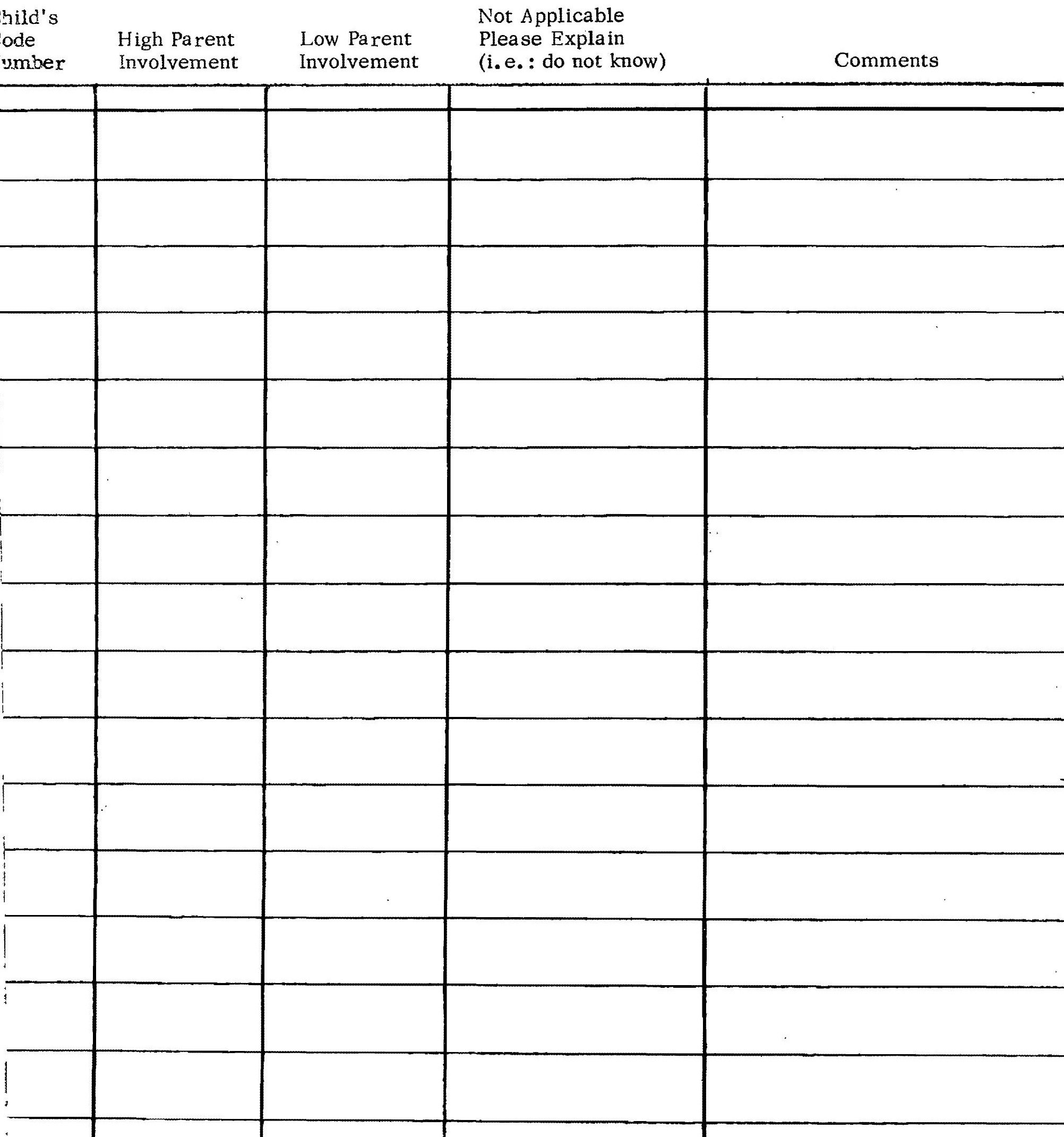


APPENDIX II

Primary Instrument 
This questionnaire is intended to gather information about children who have left the Day Treatment Center and about their families. It comes in three parts. The first part concerns what kind of help the children are now getting. The second part concerns family changes that may affect the way a child behaves. The third part concerns how the child is behaving now.

Please answer all questions as best you can. All information given will be kept confidential. Thank you for your cooperation.

\section{Part I}

Please check the boxes that describe kind of help for emotional or behavioral problems that your child or your family may now be receiving.

1. Child is now getting professional help. a. Who is he or she seeing (psychiatrist, psychologist, school
counselor, social worker, medical doctor, special teacher, special classes)?

b. How often (daily, weekly etc.)?

2. Child is now getting help from someone not mentioned above. a. Who?

b. How often?

3. Others in the family have contact with the person or agency that $i . s$ working with the child.

a. What person or agency is the contact with?

b. Who in the family besides the child has contact with the person or agency?

c. What kind of contact (group meetings, individual meetings, classroom visits)?

d. How often (if there is more than one kind of contact, please note how often for each kind)? 


\section{Part II}

Please check the boxes that describe family changes that have happened since the child has left the day treatment program.

1. Family has moved.

$\bigcirc$ a. How many times?

b. To where (another neighborhood, new town, new state)?

2. Family income has changed.

$\triangle$ a. Is there more money available for spending?

b. Is there less money available for spending?

c. How recently did this change happen (a month ago, a year ago)?

3. There has been a serious illness in the family household.

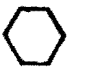

a. Which family member (father, mother, grandfather, other)?

b. What kind of illness?

c. How long has he or she been ill?

4. There has been a change in the number of people living at home.

a. Who has moved in (relative, friend, father, stepfather, mother, stepmother, other relative)?

When did this happen?

How close are they to the child (very close, not close)?

b. Who has moved out?

When did this happen?

How close are they to the child (very close, not close)?

5. There have been other important family changes not mentioned above. If so, please describe

Any other comments you wish to make: 
Part 111

Below is a list of thirty-four behavior descriptions. To the right of each description are numbers from one to seven. Please circle the number which tells how often the child's behavior has happened in the past six weeks according to the scate below. (Example: Item number 22. If a child has friends sometimes, but bis no fricnds during some weeks, circle number 4 "sometimes".)

1-CONSTANTLY - Behavior is seen constantly throughout the day.

2-VERY FREQUENTLY - Behavior is seen at least once a day.

3-FREQUENTLY - Behavior is seen at least once a week.

4-SOMETIMES - Behavior is seen more often than once a month, but less than once a week.

5-OCCASIONALLY - Behavior is seen at least once

a month.

6-SELDOM - Behavior is seen less than once

a month.

7-NEVER - Behavior does not occur.

THE CHILD:

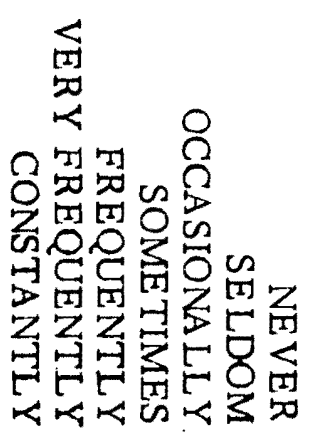

1. Protests about other's unfairness or discrimination towa rds him/her.

$\begin{array}{lllllll}1 & 2 & 3 & 4 & 5 & 6 & 7\end{array}$

2. Appears listless and tired.

$\begin{array}{lllllll}1 & 2 & 3 & 4 & 5 & 6 & 7\end{array}$

3. Conforms to limits without control from others.

$\begin{array}{lllllll}1 & 2 & 3 & 4 & 5 & 6 & 7\end{array}$

4. Becomes hysterical, upset or angry when things do

12234567 not go his/her way.

5. Completes tasks attempted.

$\begin{array}{lllllll}1 & 2 & 3 & 4 & 5 & 6 & 7\end{array}$

6. Other children act as if he/she were taboo or tainted.

1223045667

7. Will destroy or take apart something he or she has made rather than show it or ask to have it displayed.

1223445667

8. Is able to concentrate for an appropriate length of time.

$1 \quad 2 \quad 3 \quad 4 \quad 5 \quad 6 \quad 7$

9. Is overactive, restless, and/or continually shifting body positions.

122304567

10. Disturbs other children, teasing, provoking fights, interrupting others.

11. Reacts to stressful situations or changes in routine with general body aches, head or stomach aches, nausea.

12. Controls temper. 
$1-$ CONSTANTLY - Behavior is seen constantly throughout the day.

2-VERY FREQUENTLY - Behavior is seen at least once a day.

3-FREQUENTLY - Behavior is seen at least once a week.

4-SOMETIMES - Behavior is seen more often than once a

month, but less than once a week.

5-OCCASIONA LLY - Behavior is seen at least once

a month.

6-SELDOM - Behavior is seen less than once

a month.

7-NEVER - Behavior does not occur.

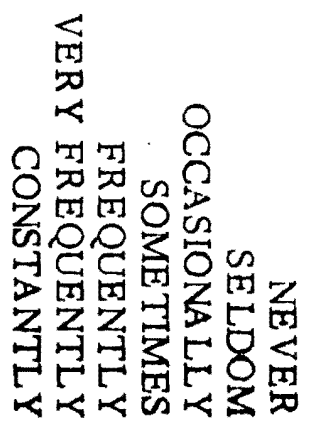

13. Has nervous tics, muscle twitches, eye blinking,

122344566 nail biting, hand wringing.

14. Comments or implies that nobody likes him/her.

$\begin{array}{lllllll}1 & 2 & 3 & 4 & 5 & 6 & 7\end{array}$

15. Utters nonsense syllables and/or babbles to self.

$\begin{array}{lllllll}1 & 2 & 3 & 4 & 5 & 6 & 7\end{array}$

16. Refers to self as dumb, stupid or incapable.

122345567

17. Participates in group activities.

$\begin{array}{lllllll}1 & 2 & 3 & 4 & 5 & 6 & 7\end{array}$

18. Repeats one idea, thought or activity over and over.

$\begin{array}{lllllll}1 & 2 & 3 & 4 & 5 & 6 & 7\end{array}$

19. When teased or irritated by other children, takes out

$1 \quad 2 \quad 3 \quad 455667$ frustrations on a nother inappropriate person or thing.

20. Has rapid mood shifts, depressed one moment, manic the next.

12334567

21. Complains of nightma res, bad dreams.

12344567

22. Has friends.

12234567

23. Expresses concern about being lonely, unhappy.

$\begin{array}{lllllll}1 & 2 & 3 & 4 & 5 & 6 & 7\end{array}$

24. Soils or wets bed or pants.

$\begin{array}{lllllll}1 & 2 & 3 & 4 & 5 & 6 & 7\end{array}$

25. Openly strikes back physically or verbally with angry behavior to the teasing of other children.

$\begin{array}{lllllll}1 & 2 & 3 & 4 & 5 & 6 & 7\end{array}$

26. Stea ls things from other children.

125345567

27. Reacts with defiance to suggestions or commands.

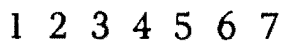

28. Is able to express self to others.

$\begin{array}{lllllll}1 & 2 & 3 & 4 & 5 & 6 & 7\end{array}$

29. Displays physical aggression towa rd objects or persons. 
1-CONSTANTLY - Behavior is seen constantly throughout the day.

2-VERY FR EQUENTLY - Behavior is seen at least once a day.

3-FREQUENTLY - Behavior is seen at least once a week.

4-SOMETIMES - Behavior is seen more often than once a month, but less than once a week.

5-OCCASIONALLY - Behavior is seen at least once

a month.

6-SELDOM - Behavior is seen less than once

a month.

7-NEVER - Behavior does not occur.

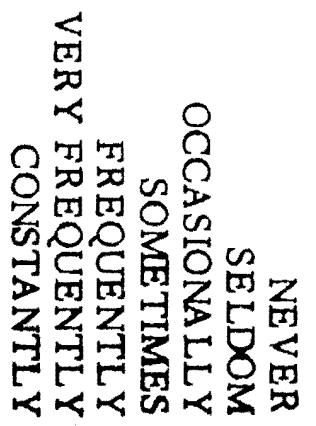

30. Protests when others hurt, tease or criticize him or her.

122345567

31 . Is able to show a range of feelings.

12334567

32. Acts perfectionistic: meticulous about having everything exactly right.

33. Stares blankly into space and is out of touch with surroundings when doing so.

34. Feelings expressed a re appropriate to the situation.

A ny other comments you wish to make: 
APPENDIX III

Caretaker Questionnaire 
This questionnaire is intended to gather information about children who have left the Day Treatment Center and about their caretakers. It comes in three parts. The first part concerns what kind of help the children a re now getting. The second part concerns environmental changes that may affect the way a child behaves. The third part concerns how the child is behaving now.

Please answer all questions as best you can. All information given will be kept confidential. Thank you for your cooperation.

Part I

Please check the boxes that describe the kind of help for emotional or behavioral problems that the child or his/her family may now be receiving.

1. Child is now getting professional help.

a. Who is he or she seeing (psychiatrist, psychologist, social worker, etc.)?

2. Child is now getting help from someone not mentioned above. a. Who?

b. How often?

3. Who in the family has contact with the person or agency that is working with the child.

a. What person is the contact with?

b. Who in the family besides the child has contact with the person?

c. What kind of contact (group meetings, individual meetings, classroom visits)?

d. How often (if there is more than one kind of contact, please note how often for each kind)? 
Part II

Please check the boxes that describe environmental changes that have happened since the child has left the day treatment program.

1. Child has moved.

a. How many times?

b. To where (another treatment unit, another program, into or out of a treatment program.

c. When did each move occur.

2. There have been changes in significant others living with the child. (This includes staff)

a. Who has entered the child's environment (specify relationship)?

When did this happen?

Significant aspects of relationship?

b. Who has left?

When did this happen?

Significant aspects of relationship? 
APPENDIX IV

Correspondence 
January 27, 1977

Dear Parent,

As graduate social work students at Portland State University, we are working with the Children's Psychiatric Day Treatment Center to try to find out what is happening with the children who have left that program during the past two years. Information about how children and their families who have already gone through the program are doing might be helpful in deciding how to make the program better for those to come.

We would like to ask for your help in doing this. Hinclosed, plcasc find a stamped envelope addressed to the Day Treatment Contcr and a form giving us permission to contact you and your child's teacher. We would like to talk to teachers because children sometimes behave differcntly at school than at home. If you are willing to have us spend a few minutes with you to gather the information we need, please complete the form, sign it and return it as soon as possible.

Please keep in mind that any information we get will be $\mathrm{kcpt}$ strictly confidential in that children's names will not be used in our report.

Thank you for your cooperation.
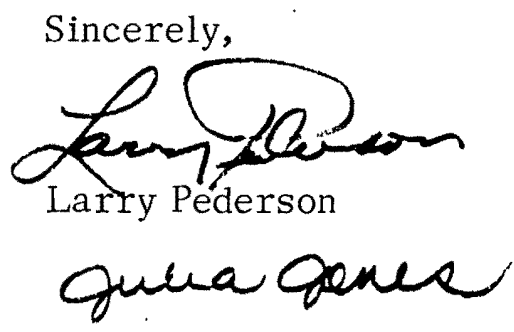

tc

Julia Jones 
Dear Parents:

This project, which has my approval, will facilitate the work of the Center in terms of its ability to evaluate and refine the quality of care being given by the program.

Thank you for your cooperation.

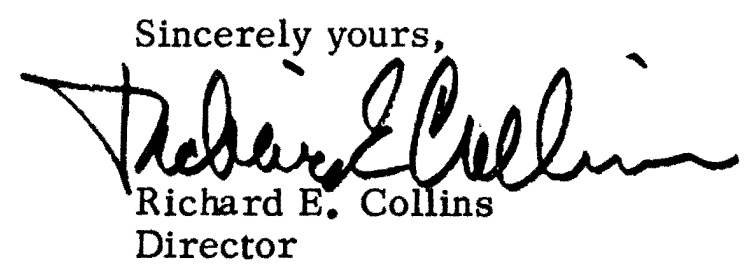

$\mathrm{REC} / \mathrm{tc}$ 
January 1:3, 1970

Dear Parent,

In late December we wrote to you asking your cooperation in a study to find out what is happening with children and their families who have gone through the Children's Psychiatric Day Treatment Center. As yet, we have received no response from you.

In order to get a fair idea of changes that happen after children go through the Center, we need to contact as many people as possible. This means that it is important for us to talk to parents who feel their children are doing well and also to parents who feel their children may not he doing. well. We need to talk both to parents who have a good opinion of the Day Treatment Center and to parents who might be critical of it.

Enclosed, please find a stamped envelope addressed to the Day Treatment Center and a form giving us permission to contact you or your child's teacher if you agree. If you are willing to have us spend a few minutes with you to gather the information we need, please complete the form, sign it, and return it as soon as possible.

Please keep in mind that any information we get will be kept confidential in that no names will be used in our report.

Thank you for your cooperation.

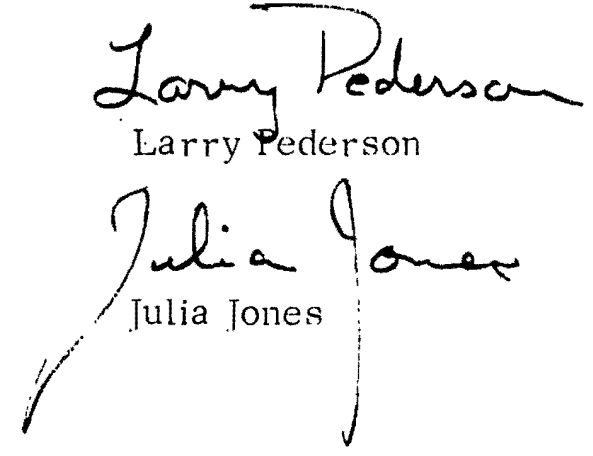


March 9, 1977

\title{
Dear Parent:
}

In my previous letter to you, I indicated that I am a graduate student working with the Children's Psychiatric Day Treatment Center. I am interested in finding out what has happened to some of the children who have gone through this program. Part of this study includes talking with the child's parents and with the child's teacher with the parents' permission. It is my hope that such a study will help improve the Day Treatment program by pointing out both its good and bad points.

I will stop by your house on Monday, March 14 at 2:00 to visit with you. If this is an inconvenient time, please let me know by calling the Day Treatment Center at 225-8068.

All information will be kept confidential in that your child's name will not be used. Your help and cooperation is greatly appreciated.

\author{
Sincerely,$$
\text { Duelici jyki. }
$$ \\ Julia Jones
}

$\mathrm{JJ} / \mathrm{Cl}$ 
Letter to CSD Worker

February 10, 1977

As graduate students at Portland State University, we are working with the Children's Psychiatric Day Treatment Center to try to find out what is happening with the children who have left that program during the past two years. Information about how children and their families who have already gone through the program a re doing might be helpful in deciding how to make the program better for those to come.

During our recent phone conversation, we agreed that I would send you the instrument we will be using to determine the child's present behavior and a consent form to be signed by you if this meets your approval. Enclosed, you will find these two items as well as an addressed envelope to the Center. All information will be kept confidential in that no names will be used.

If you have any further questions concerning our project, you may contact either of us at $225-8068$.

Thank you for your cooperation.

Sincerely,

Julie Jones

$\mathrm{JJ} / \mathrm{tc}$

Larry Pederson

enclosures 


\section{Letter to Teacher}

Our recent phone conversation indicated your willingness to participate in a research project involving a child in your class. Wo: appreciate your willingness to help with this integral part of the study.

Enclosed please find: 1) a copy of the behavior checklist we anc using. When filling this out please note that we are looking only at $x^{2}$ havior which has occurred during the past six weeks. Also, try to kecp in mind that the times noted on the frequency scale for each behavior ("at least once a day", "at least once a week" etc.) are more important than the terms used to designate these times ("very frequently". "requently" etc.). 2) a signed document by the parent allowing the information on the checklist to be released. "This is for your rocords. 3) at stamped envelope addressed to the Children's Psychiatric: Day Troatmon Conter and 4) the name of the child to be rated on a separate sheet of paper.

When you have completed the checklist. please put it in the cnvelope and drop it in the mail as soon as possible.

For reasons of confidentiality, the checklists are coded and therefore the sheet with the child's name on it may be destroyed when you are finished.

Again. thanks for your cooperation. Please note that the success of our study demands that we gather our information within a limited time period. Your reply within the next week would be appreciated.

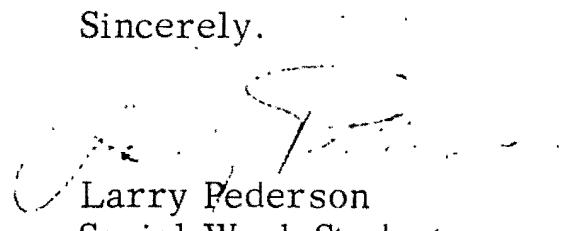

Social Work Student

Julia Jones

Social Work Student

$\mathrm{LP} / \mathrm{cl}$

encls: \& 


\section{APPENDIX V}

\section{Consent for Release of Information}

I agree that you may contact me and my child's teacher and use the information you get in your study.

I agree that you may contact me, but I wish to discuss further how your information will be used and whether you may contact my child's teacher.

$\bigcirc$ I do not wish for you to have contact with either me or my child's teacher.

I understand that any information that I or my child's teacher may provide will be kept confidential in that my child's name will not be used.

Date

$11 / 76$ 


\section{APPENDIX VI}

CHILDREN'S SCORES ON THE ADAPTED WALKER AND THEIR CHANGE SCORES

\begin{tabular}{|c|c|c|c|c|c|c|}
\hline Child & $\begin{array}{l}\text { Time } 1 \\
\text { Score }\end{array}$ & $\begin{array}{l}\text { Time } 2 \\
\text { Score }\end{array}$ & $\begin{array}{c}\text { Change Score } 1 \\
\left(\mathrm{~T}_{2}-\mathrm{T}_{1}\right)\end{array}$ & $\begin{array}{l}\text { Time } 3 \\
\text { Score }\end{array}$ & $\begin{array}{c}\text { Change Score } 2 \\
\left(\mathrm{~T}_{3}-\mathrm{T}_{2}\right)\end{array}$ & $\begin{array}{c}\text { Change Score } 3 \\
\left(\mathrm{~T}_{3}-\mathrm{T}_{1}\right)\end{array}$ \\
\hline 1 & 145 & 195 & 50 & 162.5 & -32.5 & $17.5^{\circ}$ \\
\hline $2^{* *}$ & 137 & 163 & 26 & 134 & -29 & -3 \\
\hline 3 & 124 & 175 & 51 & 149.5 & 125.5 & -25.5 \\
\hline 4 & 135 & 195 & 60 & 131 & -64 & -4 \\
\hline 5 & 145 & 190 & 45 & 156 & -34 & 11 \\
\hline 6 & 128 & 173 & 45 & 144 & -29 & 16 \\
\hline 7 & 156 & 185 & 29 & 155.5 & -29.5 & -0.5 \\
\hline 8 & 140 & 153 & 13 & 180.5 & 27.5 & 40.5 \\
\hline 9 & 112 & 178 & 66 & 154 & -24 & 42 \\
\hline 10 & 139 & 176 & 37 & 178 & 2 & 39 \\
\hline 11 & 135 & 181 & 46 & 153 & -28 & 18 \\
\hline 12 & 133 & 186 & 53 & 207 & 21 & 74 \\
\hline 13 & 103 & 161 & 58 & 174 & 13 & 71 \\
\hline 14 & 151 & 199 & 48 & 172 & -27 & 21 \\
\hline 15 & 168 & 188 & 20 & 157 & -31 & -11 \\
\hline 16 & 174 & 195 & 21 & 205.5 & 10.5 & 31.5 \\
\hline 17 & 143 & 166 & 23 & 146 & -20 & 3 \\
\hline 18 & 129 & 181 & 52 & 174 & -7 & 45 \\
\hline $19^{x}$ & 118 & 163 & 45 & 176 & 13 & 58 \\
\hline 20 & 120 & 172 & 52 & 189.5 & 17.5 & 69.5 \\
\hline 21 & 106 & 153 & 47 & 136.5 & -16.5 & 30.5 \\
\hline 22 & 152 & 168 & 16 & 191.5 & 23.5 & 39.5 \\
\hline
\end{tabular}


APPENDIX VI (cont.)

\begin{tabular}{lcccccc}
\hline Child & $\begin{array}{c}\text { Time } 1 \\
\text { Score }\end{array}$ & $\begin{array}{c}\text { Time 2 } \\
\text { Score }\end{array}$ & $\begin{array}{c}\text { Change Score } 1 \\
\left(\mathrm{~T}_{2}-\mathrm{T}_{1}\right)\end{array}$ & $\begin{array}{c}\text { Time } \\
\text { Score }\end{array}$ & $\begin{array}{c}\text { Change Score 2 } \\
\left(\mathrm{T}_{3}-\mathrm{T}_{2}\right)\end{array}$ & $\begin{array}{c}\text { Change Score 3 } \\
\left(\mathrm{T}_{3}-\mathrm{T}_{3}\right)\end{array}$ \\
\hline 23 & 178 & 195 & 17 & 159.5 & -35.5 & -18.5 \\
24 & 145 & 202 & 57 & 162 & -40 & 17 \\
25 & 154 & 176 & 22 & 158 & -18 & 4 \\
$26^{*}$ & 140 & 149 & 9 & 145 & -4 & 5 \\
27 & 148 & 179 & 31 & 155 & -24 & 7 \\
$28^{*}$ & 143 & 167 & 24 & 145 & -22 & 2 \\
$29^{*}$ & 162 & 183 & 21 & 192 & 9 & 30 \\
$30^{*}$ & 139 & 128 & -11 & 109 & -19 & -30 \\
$31^{*}$ & 177 & 177 & 0 & 155 & -22 & -22 \\
32 & 182 & 187 & 5 & 145 & -42 & -37 \\
33 & 106 & 168 & 62 & 153.5 & -14.5 & 47.5 \\
\hline \multirow{2}{*}{ Means } & 141.4 & 175.97 & 34.57 & 160.79 & -151.8 & 19.36 \\
\hline
\end{tabular}

\footnotetext{
* = Children in Institutions

$* *=$ Parent Refused School Visit
} 


\section{APPENDIX VII}

TEACHING PARENT AND INSTITUTIONAL RATINGS

ON THE ADAPTED WALKER FOR CHILDREN

AT TEST TTME 3

\begin{tabular}{|c|c|c|c|c|c|}
\hline Child & $\begin{array}{l}\text { Parent's } \\
\text { Rating }\end{array}$ & $\begin{array}{l}\text { Institutional } \\
\text { Rating }\end{array}$ & $\begin{array}{l}\text { Teacher's } \\
\text { Rating }\end{array}$ & Mean & $\begin{array}{c}\text { Difference } \\
\text { (Teaching-Parent) }\end{array}$ \\
\hline 1 & 160 & . . . & 165 & 162.5 & 5 \\
\hline 2 & $134^{*}$ & . . . & . . . & 134 & . . \\
\hline 3 & 114 & . . & 185 & 149.5 & 71 \\
\hline 4 & 142 & . . . & 120 & 131 & -22 \\
\hline 5 & 154 & . . . & 158 & 156 & 4 \\
\hline 6 & 143 & . . . & 145 & 144 & 2 \\
\hline 7 & 148 & . . . & 163 & 155.5 & 15 \\
\hline 8 & 183 & . . & 178 & 180.5 & -5 \\
\hline 9 & 146 & . . & 162 & 154 & 16 \\
\hline 10 & 183 & : . & 173 & 178 & -10 \\
\hline 11 & 139 & . . . & 167 & 153 & 28 \\
\hline 12 & 183 & . . . & 231 & 207 & 48 \\
\hline 13 & 152 & - . & 196 & 174 & 44 \\
\hline 14 & 169 & - . & 175 & 172 & 6 \\
\hline 15 & 181 & . . & 133 & 157 & -48 \\
\hline 16 & 193 & $\therefore$ & 218 & 205.5 & 25 \\
\hline 17 & 163 & . . & 129 & 146 & -34 \\
\hline 18 & 188 & . . & 160 & 174 & -18 \\
\hline 19 & . . & 176 & - . & 176 & . . . \\
\hline
\end{tabular}


APPENDIX VII (cont.)

\begin{tabular}{|c|c|c|c|c|c|}
\hline Child & $\begin{array}{l}\text { Parent's } \\
\text { Rating }\end{array}$ & $\begin{array}{l}\text { Institutional } \\
\text { Rating }\end{array}$ & $\begin{array}{l}\text { Teacher's } \\
\text { Rating }\end{array}$ & Mean & $\begin{array}{c}\text { Difference } \\
\text { (Teaching- Parent) }\end{array}$ \\
\hline 20 & 206 & . . . & 173 & 189.5 & -33 \\
\hline 21 & 153 & . . . & 120 & 136.5 & -33 \\
\hline 22 & 192 & $\cdot \cdot \cdot$ & 191 & 191.5 & -1 \\
\hline 23 & 159 & . . & 160 & 159.5 & 1 \\
\hline 24 & 164 & . . . & 160 & 162 & -4 \\
\hline 25 & 186 & . . . & 130 & 158 & -56 \\
\hline 26 & . . & 145 & . . . & 145 & . . \\
\hline 27 & 138 & $\cdot \cdot \cdot$ & 172 & 155 & 34 \\
\hline 28 & . . & 145 & . . & 145 & . . \\
\hline 29 & $\cdot \cdot \cdot$ & 192 & . . & 192 & . . \\
\hline 30 & $\cdot \cdot \cdot$ & 109 & $\cdot \cdot \cdot$ & 109 & . . \\
\hline 31 & . . & 155 & . . & 155 & . . \\
\hline 32 & 153 & . . . & 137 & 145 & -16 \\
\hline 33 & 183 & $\cdot \cdot \cdot$ & 124 & 153.5 & -59 \\
\hline $\bar{x}$ & 163.296 & 153.67 & 162.5 & 160.79 & -1.54 \\
\hline
\end{tabular}

* Parent refused to give permission to contact school. 


\section{APPENDIX VIII}

\section{PARENT INVOLVEMENT BETWEEN TERMINATION AND \\ FOLLOW-UP AND BEHAVIOR CHANGE BETWEEN \\ TERMINATION AND FOLLOW-UP}

\begin{tabular}{c|c|c|c|c|c|c|c|c}
\hline Child & $\begin{array}{c}\text { Involvement } \\
\text { Index }\end{array}$ & $\begin{array}{c}\text { Change } \\
\text { Score }\end{array}$ & Child & $\begin{array}{c}\text { Involvement } \\
\text { Index }\end{array}$ & $\begin{array}{c}\text { Change } \\
\text { Score }\end{array}$ & $\begin{array}{c}\text { Involvement } \\
\text { Child }\end{array}$ & $\begin{array}{c}\text { Change } \\
\text { Score }\end{array}$ \\
\hline 1 & 0.5 & -32.5 & 12 & .5 & 21 & 23 & 0 & -35.5 \\
2 & 4 & -29 & 13 & 3 & 13 & 24 & 8 & -40 \\
3 & 0 & -25.5 & 14 & 4 & -27 & 25 & 4 & -18 \\
4 & 1.3 & -64 & 15 & 0.75 & -31 & 26 & 1 & -4 \\
5 & 1 & -34 & 16 & 0 & 10.5 & 27 & 22.75 & -24 \\
6 & 0.3 & -29 & 17 & 4 & -20 & 28 & 6 & -22 \\
7 & 2 & -29.5 & 18 & 1 & -7 & 29 & 6 & 9 \\
8 & 0.25 & 27.5 & 19 & 4.75 & 13 & 30 & 0.3 & -19 \\
9 & 0.75 & -24 & 20 & 4 & 17.5 & 31. & 2 & -22 \\
10 & 0 & 2 & 21 & 6.5 & -16.5 & 32 & 1.5 & -42 \\
11 & 0.5 & -28 & 22 & 1 & 23.5 & 33 & 0 & -14.5 \\
\hline
\end{tabular}




\section{APPENDIX IX}

FAMILY STRESS AND BEHAVIOR CHANGE BETWEEN TERMINATION AND FOLLOW-UP

\begin{tabular}{|c|c|c|c|c|c|c|c|c|}
\hline Child & $\begin{array}{l}\text { Stress } \\
\text { Factor }\end{array}$ & $\begin{array}{l}\text { Change } \\
\text { Score }\end{array}$ & Child & $\begin{array}{l}\text { Stress } \\
\text { Factor }\end{array}$ & $\begin{array}{l}\text { Change } \\
\text { Score }\end{array}$ & Child & $\begin{array}{l}\text { Stress } \\
\text { Factor }\end{array}$ & $\begin{array}{c}\text { Change } \\
\text { Score }\end{array}$ \\
\hline 1 & 0 & -32.5 & 12 & 16.7 & 21 & 23 & 3.3 & -35.5 \\
\hline 2 & 12.5 & -29 & 13 & 16.7 & 13 & 24 & 16.7 & -40 \\
\hline 3 & 16.7 & -25.5 & 14 & 16.7 & -27 & 25 & 13.8 & -18 \\
\hline 4 & 11.1 & -64 & 15 & 100 & -31 & 26 & 8.7 & -4 \\
\hline 5 & 16.7 & -34 & 16 & 16.7 & 10.5 & 27 & 11.8 & -24 \\
\hline 6 & 16.7 & -29 & 17 & 10 & -20 & 28 & 23.1 & -22 \\
\hline 7 & 33.3 & 29.5 & 18 & 3.5 & -7 & 29 & 16.7 & 9 \\
\hline 8 & 100 & 27.5 & 19 & 10.3 & 13 & 30 & 20.7 & -19 \\
\hline 9 & 100 & -24 & 20 & 14.3 & 17.5 & 31 & 18.2 & -22 \\
\hline 10 & 5 & 2 & 21 & 31 & -16.5 & 32 & 6.9 & -42 \\
\hline 11 & 33.3 & -28 & 22 & 0 & 23.5 & 33 & 11.1 & -14.5 \\
\hline
\end{tabular}

